\title{
Organizational Design and Adaptation in Response to Crises: \\ Theory and Practice
}

\author{
Zhiang Lin \\ School of Management \\ University of Texas at Dallas \\ Richardson, TX 75083 \\ Phone: (972) 883-2753; Fax: (972) 882-2799 \\ E-mail: zlin@utdallas.edu \\ Kathleen M. Carley \\ Department of Social and Decision Sciences \\ Carnegie Mellon University \\ Pittsburgh, PA 15213 \\ Phone: (412) 268-3225; Fax: (412) 268-6938 \\ E-mail: kathleen.carley@cmu.edu
}

July 3, 2002

We would like to thank Douglas Wholey and three anonymous reviewers of the 2001 Academy of Management Annual Meeting for their constructive comments on an earlier version of the manuscript. An earlier short version of the paper was included in the 2001 Academy of Management Best Papers Proceedings, Washington, D.C. 


\title{
ORGANIZATIONAL DESIGN AND ADAPTATION IN RESPONSE TO CRISES: THEORY AND PRACTICE
}

\begin{abstract}
Organizations are occasionally faced with technologically based and accident triggered crises that can be extremely costly. An example is Bhopal, a major chemical spill. In the aftermath of such a disaster, organizations, both the one that suffered and others in the same or similar industries, often reexamine how they are structured. The questions arise: how should organizations be designed if they are to perform well in such crises, and would organizations benefit from structural changes during crises? We address these questions using a combination of computational analysis and archival data on 69 real organizations faced with crises. For each crisis incident, we contrast the organization's predicted and actual performance in a crisis situation. We find a high level of validation for the computational model. Using the validated computational model we then go on to address the hypothetical question: what is likely to have happened if the real organization had responded differently to the crisis. The findings show that there is no guarantee that a well performing organization in a general situation will continue to do so during a crisis situation. In addition, how to design or restructure an organization to mitigate the impact of crises will depend on the various design factors the organization employs. This work further demonstrates that often, the lessons learned by organizations when responding to crisis situations may be exactly the wrong lessons.
\end{abstract}

Key Words: Organizational Design, Crises, Computer Modeling 


\section{INTRODUCTION}

Organizational scholars have typically focused on events that are stable, routine, and predictable for theory development. This leaves the question of whether theories of organizations can be applicable to nonconventional events or crisis situations largely assumed and certainly not fully explored (Marcus and Nichols 1999; Carley and Harrald 1997). Crises induced by accidents are especially worthy of attention, as they can and do occur within organizations, which, if not handled properly, can result in devastating disasters. Classic cases, such as the Exxon Valdez (Harrald, Marcus, and Wallace. 1990), Challenger (Roberts 1997; Sagan 1997; Weick 1997; Vaughan 1990), and Bhopal (Shrivastava 1987) are now important managerial case studies. The bulk of research in crisis management, however, has relied heavily on conventional case methods and focused exclusively on preventing crises. Often, findings have become listings of rhetorical suggestions that lack both the theoretical background and the quantitative foundation. As some researchers have pointed out, there are insufficient studies on how aspects of organizational design and task environment interact to affect organizational performance in these crisis situations (Lin 2001; Pearson and Mitroff 1993).

Crises faced by organizations often have their roots in both the external environment faced by the organization and in malfunctions within the organization (March and Simon 1958; Perrow 1984). For example, causes of the Exxon Valdez oil spill include external factors such as a treacherous coastline and poor weather conditions, and internal factors such as human error and organizational culture (Harrald, Marcus, and Wallace 1990). Similarly, causes of the U.S.S. Vincennes shooting down an Iranian air flight (Rochlin 1991) include external factors such as cultural bias toward superpower confrontation (Duffy, Kaylor, and Cary 1988; Watson, Barry, and Sandza 1988), and internal factors such as training, data misinterpretation (Cohen 1988), incorrect information (U.S. Congress 1988), and the hierarchical structure of the Navy warship (Watson, Barry, and Sandza 1988). Clearly, during crisis situations, external and internal causes are often compounded. Typically, crises are multi-causal and have the potential for catastrophic consequences (Carley and Harrald 1997). Thus, organizational performance during a crisis becomes a function of many factors including training, expertise, and organizational design. Indeed, recent 
work on adaptive organizations suggests that design and expertise work synergistically to effect performance, particularly in non-routine settings (Hollenbeck, Ilgen, Sego, Hedlund, Major, and Phillips 1995a; Hollenbeck, Ilgen, Tuttle and Sego 1995; Carley 1996; Levinthal and Warglien 1999; Carley 2002a). Moreover, the path followed may affect long run strategic change and learning in the organization (Kim 1998; Carley, 2002b).

In contrast to this adaptive approach, much of the previous research on technology based and accidenttriggered crisis has focused on avoidance. The basic idea was that a well performing organization should be able to avoid crises and so there will not be a need for it to actually face crises. However, as Perrow (1984) and Rochlin (1991) noted, crises are essentially inevitable, especially in large and complex systems. Reason (1998) even argued that the avoidance is not only impossible but in reality has not been successful due to the necessity of human involvement. If crises are indeed inevitable, then the more important question is not about how to design the organization to avoid crisis, but how to design the organization for high performance during a crisis. Re-framing the question in this way gives rise to an entire new set of concerns. Is the organizational design that exhibits high performance during a crisis also optimal under non-crisis conditions? Is it reasonable for organizations to design for crisis, or should organizations alter their designs when faced with a crisis? In other words, is dynamic adaptation called for? Further, if organizations do restructure, what will be the most effective new structure?

At the heart of the issue is that, as noted by March and Olsen (1976), organizations are composed of boundedly rational individuals. These individuals are continually beset by ambiguities (such as missing information and agent unavailability) that can result in crises, which can potentially impair performance. For example, in the 1988 Hinsdale incident, the devastating telecommunications outage in the Chicago area resulted from the co-occurrence of a large number of internal sub-optimal situations such as agent unavailability and missing information (Pauchant et al. 1990). Marcus and Nichols (1999) also find that organizational resource unavailability and misuse can cause individuals to neglect apparent warning signals of crises and compromise the safety of organizations. Organizational decisions, which underlie all organizational activity, rest on the way in which the individuals in the organization gather, process and 
communicate information (Simon 1947; Scott 1987). Factors inhibiting information processing lead to incorrect decisions and so less accurate organizational decisions and so worse performance. Inaccurate decisions, particularly in a crisis situation, can have devastating consequences. Organizations with designs that facilitate information processing and accurate decision-making should enable higher overall performance during crisis situations.

In this paper we focus on the question of design. We do not ask the extent to which crisis degrades performance. Nor do we ask how organizations can be designed to avoid crises, even though an ideal organization should be able to avoid crises and adapt well. While these are important questions, they are not ours. Rather, we are interested in asking, given that a crisis has occurred, what organizational design fares best? Our methodological approach is somewhat novel. First, we have a fairly traditional empirical database with the design and performance features of 69 organizations faced with technological crises. Second, we have accumulated a series of findings about organizational behavior and individual decisionmaking and used these to create a multi-agent simulation model of organizational performance, which we refer to as CORP (Carley and Lin 1997). Using this simulation model, we run series of matched simulations; i.e., we simulate each of the 69 cases, with the designs in the simulator chosen to match the design characteristics of the real organization. We use this to predict the performance of the real organizations. Then we statistically compare the predicted and actual outcomes. Then, we go one step further and ask a question that is only possible in a combined simulation and empirical study, and that is, what if the organizations that dynamically shifted their designs in response to the crisis had not done so? Even though the empirical part covers only a small range of organizations compared with what the computer simulation model can predict, this study can provide new insight into the impact of design on performance, organizational adaptability, and demonstrates a unique analytic method for theory development in the area of organization science.

\section{BACKGROUND}

That organizational performance is affected by design is highly documented (Baligh, Burton, and Obel 1990; Mackenzie 1978; Scott 1987). The growing interest in high reliability has further led researchers and 
managers to explore organizational designs suited to high performance under stress and non-routine situations (Bigley and Roberts, 2001; Roberts 1990). An outgrowth of this interest is the suggestion of a new organizational form in which temporary incident response systems are employed during a crisis situation to mitigate or even eliminate the impact of a potential crisis. Despite this suggestion, research has demonstrated that there is no one best design across all conditions (Carley 1992; Lin and Carley 1997). However, whether there exists a class of designs that, while not optimal, are nevertheless good enough and robust in the face of crises has not been addressed.

We define a crisis to be a critical situation that can have severe negative consequences to the organization if not handled properly (Carley and Lin 1995; Perrow 1984). Specifically, we focus on technology based and accident triggered crises; rather than economic based disasters or natural disasters. Crises can be very costly for organizations. Errors during a crisis may be more costly than at other times. Thus, the relative benefits of different designs should be more easily observed during a crisis. Studies have shown that crises can degrade organizational performance and that organizational design can be an important factor in mitigating the impact of the crisis (Carley and Harrald 1997; Perrow 1984; Shrivastava 1987). However, there are few studies that compare organizational designs with an eye to performance across a wide number of crises (two such studies are Drabek and Hoetmer 1991; Tamminga, Kilijanek and Adams 1981) and none that compares actual organizational behavior with a formal model.

Despite this dearth, the literature is filled with suggestions with regard to how to design for crisis. One suggestion, advocated by Thompson (1967), Mintzberg (1979), La Porte and Consolini (1991), and Roberts (1990), is that organizations can buffer the impact of crisis and make fewer erroneous decisions through loose coupling or structural redundancy. Hermann (1963), Staw, Sanderlands, and Dutton (1981), and Mackenzie (1978), however, point to the value of highly centralized but not necessarily redundant structures in managing crisis. Shaw (1981) notes that decentralized organizations can respond quickly to complex tasks and so should perform better during crisis situations. The allocation and access of resource has also been emphasized as a vital part of organizational survival especially in crises where resources become extremely scarce (Pfeffer and Salancik 1978). It has also been suggested that heedful interaction among organizational 
members can increase the reliability of organizational performance when faced with crisis (Weick and Roberts 1993). It also appears that the impact of a crisis can be reduced simply by giving personnel the right training (Perrow 1984; Shrivastava 1987). However, the work by Price and his associates (Price 1977; Price and Mueller 1981) suggests that training can reduce flexibility, which could impair the organization's ability to respond during crisis. A similar argument is that planning, in the form of preparation for contingent events, can maintain performance under crisis (Baligh, Burton, and Obel 1990; Schoonhoven 1981). Stress has also been suggested as the main cause for uncertainties and ambiguities that put organizations in suboptimal conditions (March and Olson 1976). However, these suggestions often conflict with each other and do not form a unified model of organizational performance under crisis. As warned by Pfeffer (1993), such fragmented and often contradicting thoughts may pose potential danger to the development of theory and scientific discovery in organization science.

In this paper, we extend this literature by developing a neo-information processing perspective (Carley and Gasser 1999) to develop a theoretical conception relating organizational design to performance both in general situations and during a crisis. We draw on work in contingency theory, information processing, dynamic network analysis, cognitive science and computer science. We compare our theoretical model (embodied as a computational model) with "reality". The computational model serves as an encapsulation of organization theory and generates a series of predictions regarding how to design an organization that is faced with crisis so that it is effective. The "reality" is a set of data concerning the relative effectiveness of 69 actual organizations faced with actual crises. Given the 69 real cases we generate a matching set of 69 artificial organizations. We compare the relative performance of the real organizations and their artificial counterpart under both general and crisis conditions. This comparison provides a partial test of the model. Many of the real organizations restructure their design when faced with a crisis. We can use the model to ask the question, would the performance of these organizations have been higher or lower if they had not been restructured. In this way, we can begin to assess the relative value of restructuring organizational design in response to crisis.

We are interested in understanding the relation between organizational design and performance, 
particularly in crisis situations. During a crisis situation it is particularly important that the organization make timely and accurate decisions in order to minimize risk, loss of life, personnel and money. It is true that organizational performance can be characterized in a number of ways including accuracy and timeliness in decision-making, market share, and stakeholder perception. Nevertheless, particularly in a crisis situation, accuracy is key. Factors that influence accuracy, in this sense, influence performance under normal operating conditions and under stress, i.e., during periods of crisis. We take a neo-information processing approach and so characterize organizations as consisting of cognitively restricted, socially situated, and task oriented actors (Carley and Prietula 1994; Carley and Gasser 1999). Organizational decisions result from the collective and integrative actions of all the actors as they work, gather information, learn, communicate and make individual decisions in an interaction-knowledge space (Carley and Hill 2001). A wide variety of previous research has indicated that organizational performance is affected by a myriad of factors including, though probably not limited to: the training of the individuals in the organization (e.g., Sgrivastava 1987), the lines of communication and command connecting these individuals (organizational authority structure and the degree of centralization) (e.g., Mackenzie 1978), the resources and information to which the individuals have access (Pfeffer and Salancik 1978), the nature of the task faced by these individuals (Baligh et al. 1990), and the type and severity of stress under which these individuals operate (Perrow 1984). Figure 1 contains a conceptual model of how design and stress influence organizational performance.

\section{*** Place Figure 1 about Here $* * *$}

We approach the analysis using a combination of empirical and computational analysis. Researchers in the crisis management field have often turned to computational models due to the complexity of the situations they are trying to understand (Havron and Blanton 1977; Rolfe, Saunders and Powell 1998; Rosenthal and Pijnenburg 1991; Walker 1995). The models employed have provided new insights into various issues of crisis management, and have largely been based n operations research and game theory approaches. We take a different approach in CORP. CORP can be thought of as a multi-agent network model of organizations that draws on the finding in contingency theory (Baligh, Burton, and Obel 1990; 
Scott 1987), information processing theory (Galbraith 1977; March and Simon 1958), and cognitive science (Newell 1990; Hutchins 1991). CORP is an explicit representation of the theory overviewed in figure 1. We believe that only a systematic examination of various external and internal factors and their impact on information processing can provide a precise and consistent analysis of organizational performance under crisis situations.

The design of this computer model has followed the call by Burton and Obel for a balance of relevancy, realism, and simplicity in computational models (Burton and Obel 1995). The computer model was based on the work by Carley and Lin in their 1997 Management Science article and has been tested and proven to be both empirically valid and methodologically reliable (Carley 1996; Carley, Prietula and Lin 1998). While simple in design, the CORP model provides a close resemblance to key real world organizational features in terms of complexity, centralization and formalization (Lin and Hui 1999). It can address the research question described and is powerful in providing insights through a balanced design of the virtual experiment.

\section{MATCHED ANALYSIS}

We examine how these various elements of design and stress impact performance for both artificial (simulated) and real (observed) organizations. We examine the behavior of 69 pairs of organizations, such that for each pair of organizations they match in their organizational design characteristics and the stress that they face. However, for each pair, one organization is real (drawn from the observed archival data sources) and the other is artificial (simulated using CORP). For each organization, both the real and artificial analog, data on the factors identified in Figure 1 is collected. For each of the real organizations we are not capturing detailed data on the specific behavior, access to resources, and position of each individual in the organizations in the crisis response unit. Rather, we are collecting data on the general way in which the organization is designed; i.e., a team with segregated information using standard operating procedures and operating under conditions of agent malfunction. The artificial organizations are constructed as computational analogs of a real world organization. The artificial organization is structured to have the same general properties as the real organization. Following are details on the coding of both real and 
artificial organizations. As will be noted, every effort was made to work at a comparable level of detail, and to create matched characteristics for both the real organization and its computational analog. The behavior of the simulated organization is then used to predict the behavior of the real organization.

\section{ARCHIVAL DATA}

Using archival sources, information was collected on the organizational design characteristics, stress, and performance of 69 organizations faced with technological disasters. These technological disasters create a crisis situation to which the organization must respond rapidly and accurately to mitigate adverse consequences. Examples of such disasters are the Three Mile Island Incident, the Space Shuttle Challenger Incident, the Vincennes Incident, and the United Flight 232 Incident (see Table 1 for a complete list and their sources). The organizations are drawn from 14 different industries including chemical, navigation, aviation, railroad, space, nuclear, construction, oil, entertainment, mining, agriculture, religion, communication, and military. In each case, the organization was faced with a crisis, which had the potentially to severely impact either human lives, the environment, or the local economy. We limit our attention to the period immediately surrounding the crisis.

$$
\text { *** Place Table } 1 \text { about Here *** }
$$

The data we have collected describe behavior of the organization immediately prior to and during the crises. We do not examine organizational behavior in the aftermath of the crisis or the cleanup stage of the crisis. The data on the 69 organizations were gathered using a variety of sources including journal articles, books, and news media. We rely primarily on detailed journal articles and books written by researchers about that specific incident. When necessary we augmented this with news reports. As suggested by March, Sproull and Tamuz (1991), we believe our approach can provide sufficient insights into the incidents for our research issues, although it may not guarantee consistent agreement on interpretations. We have compiled information on each case about organizational design, stress, and organizational performance.

For each case we coded 31 variables related to design, stress and performance. A codebook, describing each variable, and how to code each variable was constructed. ${ }^{1}$ An excerpt of the codebook related to the organizational authority structure is illustrated in Figure 2. Codebook entries provide criteria 
for making the coding judgment. They also contain a case example. Using this codebook all 69 cases were coded. To validate the coding, we randomly picked four cases from the 69 . We had another individual, who has little knowledge of our research, code these cases using the codebook. On average, for the 31 items in each case, the inter-rater reliability is $89 \%$. Most disagreements that occurred were on exactly which value to use on Likert Scale questions.

*** Place Figure 2 about Here ***

For each organization, we have both pre-crisis and during crisis data. We identify a crisis period as the time from the beginning of the incident to the end of the incident. The beginning of the incident occurs when the first signal of the incident is detected by the organization. The end of the incident occurs when the incident is under control and the possibility of escalation has ended. For some incidents, this period can last only a few seconds, for others it can last for days. We measure for each relevant variable (e.g., organizational authority structure, and resource access) its value prior to the crisis and during crisis. For some variables, however, the crisis length, even when it amounts to days, is sufficiently short that no changes occur in that variable (e.g., training).

\section{Task Environment}

We examine several types of task environments characterized by decomposability and concentration.

\section{Decomposability}

Decomposable. In this type of the environment, the components of the task faced by the organization can be processed independently. For example, in the Challenger incident (Case No. 57), the task environment is regarded as decomposable as the work was mainly a combination of numerous contractors' products.

Non-decomposable. In this type of the environment, the components of the task faced by the organization are dependent on each other to be processed. For example, in the Three Mile Island incident (Case No. 51), the task environment is regarded as non-decomposable as the basic work of the nuclear plant was not separable from each other.

\section{$\underline{\text { Concentration }}$}


Concentrated. In this type of task environment, organizations tend to face more hostile problems that may bear grave consequences. For example, in the Vincennes incident (Case No. 68), the task environment is regarded as concentrated as most aircraft were of enemy nature.

Dispersed. In this type of the task environment, organizations face problems of different natures, with no type of problem dominating. For example, in the Chemstar incident (Case No. 8), the task environment is regarded as dispersed as the daily operations the organization faced that were of dangerous and nondangerous natures are about equal.

\section{Organizational Design}

Referring back to Figure 1 we see that organizational design can be characterized in terms of organizational authority structure, resource access structure, and training.

\section{Organizational Authority Structure}

All organizations are characterized into one of the following two structures: team or hierarchy.

Team. In this structure, communication links are predominantly lateral. Final decisions are collective actions of the group. The group can either have a dominant leader or make decision through democratic processes. For example, in the Louisiana mine incident (Case No.56), the workers formed a group and there was virtually no one with the most power. This is essentially a team structure. In the Three Mile Island incident (Case No.51), the organization of the control room is a typical team as there was a group of operators working under a manager.

Hierarchy. In this structure, communication is predominantly vertical, flowing between organizational levels. Some of the communication may across multiple divisions. The top-level is the key decision making body and has the most power. For example, in the Vincennes incident (Case No.68), the organization had three levels of management, mainly, radar operators, supervisors, and the commanding officer (the captain) and is therefore a hierarchy. Also in the Ashland oil spill incident (Case No.46), the organization had several hierarchical organizations working under several common managers and is therefore also a hierarchy structure.

\section{$\underline{\text { Resource Access Structure }}$}


We consider two types of resource access: segregated and non-segregated.

Segregated. In this structure, each member directly responsible for daily operation processes a basic component of the task. There is virtually no overlap or sharing of the components among team members. For example, in the Vincennes incident (Case No.68), each radar operator was responsible for one part of the radar equipment, and there was no overlap in responsibilities.

Non-segregated. In this structure, each member directly responsible for daily operation processes more than one basic component of the task. There is some overlap and sharing of the components among the team members. For example, in the Apollo-13 incident (Case No.58), the operators in the control room perform several actions in common (in order to double check each other) and do some tasks in isolation.

\section{$\underline{\text { Training }}$}

We examine two training scenarios: operationally trained, and experientially trained.

Operationally trained. In this training scenario, the members of the organization immediately responsible for the daily operation follow strict routine procedures. Personnel are trained on and expected to follow standard operating procedures to make decisions. For example, in the Vincennes incident (Case No.68), radar operators were trained to follow strict procedures.

Experientially trained. In this training scenario, the members of the organization responsible for the daily operation mainly follow prior experience of similar problems. For example, in the Ashland oil spill incident (Case No.46), personnel were encouraged to follow their experience in making decisions.

\section{Crisis}

Each organization was selected because it was faced with a technological disaster. We note that these events have the potential, if not handled properly, to result in severe consequences in the areas of human life, environment, or monetary considerations. Technological disasters are inevitable, but nevertheless unlikely. During a disaster period the organization typically faces sub-optimal operating conditions. Suboptimal operating conditions are internal organizational failures information uncertainty or agent malfunction. These internal sub-optimalities may or may not trigger the crisis, however, in all cases, they occur or continue during the crisis. 
In these organizations multiple types of sub-optimalities can occur at the same time. We have information on the types of sub-optimalities and an indication of their severity. We do not have information on the number of same type of sub-optimality that occur simultaneously.

Information uncertainty. Information uncertainty occurs when one or more of pieces of information needed to make decisions that are related to the organizational operation are incomplete or incorrect. For example, in the United 232 incident (Case No.35), the pilot lacked the necessary information to operate the airplane under certain emergency conditions.

Agent malfunction. Agent malfunction occurs when one or more members of the organization are not at their post, are unable to communicate, or are replaced by new personnel when they are needed to make decisions that related to the organizational operations. For example, in the Hinsdale Telecommunication incident (Case No.67), no operator was on site to take care of the control room when it was on fire.

\section{Organizational Performance}

For the 69 organizations, performance cannot be measured simply as accuracy of the decision choice. This is because the "true state" is often unknown. Thus, we take a qualitative approach to measuring general performance and performance during crisis.

Organizational performance in general. For the 69 cases, general performance takes into account: a) the frequency with which sub-optimal internal operating conditions had previously occurred in this organization (prior to those involved in this crisis) which could have resulted in a crisis; b) the frequency of similar crises; and c) the reputation of the organization in the local society. Organizations with good previous operating conditions, who had faced few crises, and who had good reputations are defined as having a high general performance. Being good on any two of these conditions is sufficient to be rated as a high performer. Being low on any two of these conditions is sufficient to be rated a low performer. All others are rated as moderate performance. For example, Vincennes is rated as having moderate general performance as it had a moderate operating condition (in part due to the lack of proper training), few similar crises, and a moderate local reputation.

Organizational performance during crisis. For the 69 cases, all organizations are faced with both 
critical external situations and sub-optimal internal conditions. According to the definition of organizational effectiveness, organizational performance is largely determined by the outcome of the organizational decision choices, such as the actual severity of the crisis (e.g., lives lost or cost). Performance, however, is also determined by the potential severity of the crisis (i.e., the chance of avoiding escalation). We code the performance of organizations during the crisis using both the actual and potential severity of the crisis.

Actual severity of crisis. We measure the severity of a crisis relative to the average severity of crises in that industry. Given the limit of information, this is a mainly qualitative measure. A crisis is considered more severe (1) if a crisis of similar magnitude (loss of life, cost of response, loss to environment) is unlikely to occur in that industry or (2) if the magnitude of this crisis is greater than the impact of other crises in the industry (Table 2). More severe crises are more rare and of greater magnitude than the average crisis in that industry. For different industries there exist various scales that provide information on the average level of crisis criticality in that industry. For example, Lagadec (1981) provided classification scales in terms of death toll for industries such as navigation, military, mining, railroad, aviation, chemical, and construction. He found that in the 20th century, the average death toll for large-scale crises in the navigation industry was above 1,500; for the military industry it was 6,000; for the chemical industry it was 500; for the railroad industry it was 60; for the aviation industry it was 30; and for the construction industry it was 100. Lagadec (1981, pp. 175) also found that the average monetary cost of a large-scale crisis was above \$25 million. We use this data to set industry standards.

*** Place Table 2 about Here $* * *$

Potential severity of crisis. We measure the potential severity for the 69 cases as the possibility of avoiding the escalation of the crisis to its largest possible magnitude after the first sign of impending crisis is detected. We adopt Perrow's (1984, pp. 344) classification scale, except that we categorize crises in the space industry as having a low chance to avoid escalation (high potential) instead of a high chance to avoid escalation (low potential). This reclassification makes sense given the changes that space technology has undergone in the past two decade. The Space Shuttle Challenger could not have been saved even if the warning signal had been detected when it was in the air. Nuclear crises, space crises, communication crises, 
and aviation crises are categorized as having a high potential. Chemical crisis, oil crises, and navigation crises are in the middle. Agricultural crises, construction crises, mining crises, railroad crises, religious crises, military crises, and entertainment crises are categorized as having a low potential severity (Table 2).

Organizational performance given that a crisis has occurred thus takes into account both the actual and potential severity of the crisis. Low organizational performance $(=1)$ is defined, as occurring when the severity of the crisis is high and the potential is low or medium. Therefore, the organization did not handle the crisis as well as it could have and so performance is considered to be low. In contrast, the organization is said to have high performance $(=3)$ when the severity of the crisis is low and the potential is medium or high. All other cases are defined to be moderate performance $(=2)$ (Table 2). For the Vincennes incident, the organizational performance is low as the actual event was severe (many people died) and the crisis was, to a large extent, avoidable.

\section{CORP: THE SIMULATION MODEL}

Using computational analysis, it is possible to examine the effect of organizational authority structures, resource access structures, training scenarios, internal sub-optimal operating conditions, and level of the severity of sub-optimal operating conditions on organizational performance. Results from the computational model can further provide theoretical directions for future empirical research. The difficulty of the empirical data collection also makes it necessary to consider the use of the computational approach. This conceptual model is embodied in the simulation framework that we refer to as CORP ${ }^{2}$ (Computational ORganizational Performance framework) (Carley and Lin 1995, 1997; Lin and Carley 1992; Lin 2000). CORP has been described in detail and its basic behavior analyzed elsewhere (Carley and Lin 1995 1997). In this paper, we present a simplified description of CORP concentrating on those aspects that are relevant to this analysis. Within CORP performance is measured in terms of average accuracy on a categorization/choice decision task. The CORP framework is a meso level multi-agent network ACTS model (Carley and Prietula 1994) in which each individual member of the organization is modeled as a cognitively restricted, socially situated, task oriented actor. The organization is modeled as a distributed environment in which organizational decisions result from the collective and integrative actions of all the individuals in a 
holistic rather than simple additive fashion. Each organization is characterized by the lines of communication (organizational structure), who has access to what resources or information (resource access structure), and the training its personnel receive. Each organization operates in a particular task environment. Each organization operates under different stresses. Within CORP each of these items is a variable that can take on several different values.

CORP is consistent with many findings in cognitive and organization science. Thus CORP can be viewed as a step toward integrating our understanding of organizational design into a single and internally consistent theory of organizational performance. Using this framework the researcher can explore many different organizational phenomena. CORP makes it possible for the researcher to consider a large number of different organizations. The CORP framework is written in UNIX C. Using this framework, it is possible to systematically alter task environments, organizational authority structures, resource access structures, training scenarios, the type of internal sub-optimal operating conditions, and the level of the severity of suboptimal operating conditions (please also see Carley and Lin 1995 1997; Lin and Carley 1992 for further details). The reader should keep in mind that within CORP, options other than those used in this paper are available.

\section{Modeling Task Problems}

In CORP, a ternary choice classification task is built for which organizations have to make repeated decisions regarding a series of quasi-repetitive problems composed of multiple factors in a distributed setting. While this is a stylized task, it can represent a wide range of organizational decision-making problems. Specifically, the organization must rely on nine indicators from the environment to classify problems into one of three types (e.g., friendly, neutral, or hostile). Each event is uniquely described by its value on nine indicators. Each indicator can take on a low, medium, or high value. A single indicator or a subset of the indicators may not reflect the true nature of the event. Also, agents are boundedly rational; i.e., no individual member has the cognitive capacity to handle neither all nine indicators nor the institutional access to all nine indicators. Organizational decisions require that each organizational member work on a subset of information, reach a recommendation or decision, and pass his or her judgment to the upper level 
manager (if any). The agents, neither individually nor collectively, have any prior knowledge of the true nature of all the problems and their distributions in the task environment. Consequently, since organizational decision-making requires coordination of only partially informed members, the agents and the organization can make misjudgments.

Classification choice tasks have been widely studied in organization science, team theory, and mathematics. The specific task used here is a ternary version of the classic binary choice task (Carley 1992; Mihaviks and Ouksel 1996) and is comparable to the team decision task used by organizational psychologists (Hollenbeck, et al. 1995a 1995b). Though highly stylized, this task resembles a large number of real world distributed decision-making. Organizational decisions do not require that the agents come to consensus; rather they require that each individual in the organization do his or her job evaluating a subset of information and passing on their judgment to other members. We define the set of choice events faced by the organization as its task environment. These types of distributed categorization/choice tasks are very common in the real world. Such choice situations include law making, price setting, planning, and a host of other similar things (Allison 1971; March and Olsen 1976; Shull et al. 1970). For example, in a manufacturing planning setting, the task can also be considered as consisting of a series of production proposals that require the organization to decide whether to produce, hold, or reject the production of certain products based on information from nine indicators such as financial status of the company, human resources, technology, customer preference, etc. Thus, an organization's decision requires coordination among various people who work with different indicators.

This choice of tasks enables us to use accuracy as an indicator of organizational performance. As previously noted, accuracy is only one-way in which performance might be conceived. For organization's faced with crisis situations it is a particularly critical measure as inaccuracy can have catastrophic consequences. Further, we find that in general, ensemble performance measured as general accuracy across a range of tasks is a general indicator of performance.

\section{Modeling Task Environments}

Organizations are open systems and so the nature of the task environment affects organizations 
(Aldrich 1979). Organizations frequently have to tackle the hostility of the environment and survive under critical external conditions. In many current organizational theories, task is treated exogenously as the problem to be solved (Mackenzie 1978) or "the sources of inputs" (Dill 1958). In CORP these ideas are captured by characterizing the task environment as the collection of choice problems faced by the organization. The two aspects of task environment that we will focus on in this research are: how task components are interrelated (decomposability) and how outcomes of tasks are distributed (concentration). These factors are related to task complexity (Aldrich 1979). Table 3 contains a detailed description of the simulated task environments that are simulated based on the manipulation of these two dimensions.

$$
\text { *** Place Table } 3 \text { about Here *** }
$$

\section{Decomposability}

Decomposability measures the interrelationship among task components. Problems of coordination may potentially occur if organizational design does not take the task environment decomposability into consideration.

Decomposable. The components of the task problems are not related to each other and the task problem can be solved with the independent processing of the task components.

Non-decomposable. The components of the task problems are related to each other and the task problem cannot be solved with the independent processing of the task components.

\section{Concentration}

Concentration measures the distribution of the true nature of all possible problems. Organizations in a concentrated task environment generally face one aspect of the task environment and therefore are operating in a narrowly defined niche. In contrast, organizations in a dispersed task environment face all aspects of the general problem and, as such, operate in a generalized niche.

Concentrated. Problems of a hostile nature are most likely to occur in the task environment.

Dispersed. Problems of all possible natures (friendly, neutral, and hostile) are equally likely to occur in the task environment.

\section{Modeling Individual Members}


In CORP, the building blocks are "agents", which can be thought of as key decision makers or decision-making units in the organization. A decision-making unit may be an individual, a division or group, or an individual or group supported by information technology that plays an identifiable decision making role in the organization. To model the organization, we create a set of "agents", each of which has the ability to learn, communicate, gather information and make decisions. Each agent can read information, make decisions, receive training (either to follow standard operating procedures or to develop their own peculiar expertise), communicate decisions, and update memories. Each agent has a particular role in the organization. This role is characterized by their position in the organizational authority structure and by what resources or aspects of the task they can access.

\section{Modeling Organizational Designs}

Organizational design has long been considered to have an effect on organizational performance. Literature in organization science has viewed organizational design from a variety of perspectives, including formal structures and task decomposition structures (Burton and Obel 1984; Mintzburgh 1983), procedures for combining information or making decisions (Panning 1986; Radner 1987), and informal mechanisms such as styles for approaching problems in organizations (Scott 1987; Sohal and Egglestone 1994). The interest in organizational design is largely due to the fact that organizations can, to some extent, alter their designs and the belief that a right design will enable organizations to achieve higher levels of performance and to be more adaptable. In this research, we follow this tradition and view the organization as an open system (Thompson 1967), in which (1) the task environment affects organizational design, process, and performance; (2) organizational members interact with the task environment and/or each other; and (3) the organization can learn. Organizational design is regarded as a combination of the organizational authority structures, resource access structures, and the decision procedures. These elements of design characterize is organization simulated.

Organizational Authority Structure

In CORP, the organizational authority structure is defined as the formal flow of command and communication among members in the organization (Hall 1991). We consider two main types of 
organizational authority structures: team and hierarchy. Both the team and the hierarchy are widely studied organizational forms and exist in actual organizations.

Team. For a team structure the organization reaches decisions through either a democratic majority voting process where either decisions are made by consensus among the members, or a team leader takes all independent decisions and integrates them into a single group decision. In this study we consider teams with nine operational personnel and at most one team leader.

Hierarchy. For a hierarchical structure, organizational decisions result from the flow of decisions made through multiple levels of communication. Bottom-level personnel process information and pass up their recommendations to their immediate managers, who in turn process this concentrated information and pass up their recommendations to the top-level manager. The top-level manager makes the ultimate organizational decision. In this study we examine organizations with nine operational personnel, three midlevel managers, and one top-level manager.

\section{$\underline{\text { Resource Access Structure }}$}

The resource access structure defines the flow of "raw" or unfiltered information or resources to personnel. The resource access structure can be thought of in terms of resource dependencies (Pfeffer and Salancik 1978) or in terms of information access (Carley 1992). We consider two types of resource access structures: segregated and non-segregated both of which are common in actual organizations.

Segregated. In this structure, each operational agent has access to one task component. There is no sharing of any component by two or more agents.

Non-segregated. In this structure, each operational agent has access to two or more task components. More than one agent accesses each task component.

\section{$\underline{\text { Training }}$}

Training is defined as the way in which personnel are taught to use information in solving problems within the organization. We consider two training scenarios: operationally trained and experientially trained.

Operationally trained. When organizational members are trained in this way, they base their judgment on standard operating procedures, which they have perfectly learned. The standard operating procedure 
employed forces members to weigh each piece of information equally and make an unbiased judgment. For example, if an operational agent uses the standard operating procedure to process three pieces of information such as "1" (pro), "2" (neutral), and "3" (con), the agent will evaluate each piece of information with the same weight and then come up with a middle decision "2" (neutral), regardless of what other personnel decide or the agent's prior experience.

Experientially trained. Organizational members with this training tend to accumulate historical information of past problems through learning from feedback. In their memories, they keep building up links that connect each possible incoming pattern of information to the frequency with which that pattern is associated with a particular outcome. In other words, they build pictures of what is likely to happen on average. Each agent makes decisions using this personal experience. The weight of each piece of incoming information will then depend on how it contributed to the previous outcomes. For example, if an operational agent uses the experientially trained procedure to process three characteristics of a problem represented as "1" (pro), "2" (neutral), and "3" (con), the agent will use the three pieces of information as an index to search his/her memory and locate the most likely outcome. If, in that agents experience, the most likely outcome given those three pieces of information is a "3" (con) then that is what the agent will report. After the problem is over, agents use the feedback on the true nature of the problem to update their memory.

\section{Crisis}

We model crises as occurring when both the external task is biased, i.e., a specialized less common task, and the internal operating conditions are sub-optimal. In CORP the external task is biased just in case the organization is faced with a choice-event is constrained to only one outcome condition. We use the "con" condition. How and when a problem is considered to have this outcome depends on the overall nature of the task environment, as described in the earlier section.

\section{Types of Sub-optimality}

The second aspect of being in a crisis situation is the presence of a sub-optimal operating condition. Internal operating conditions can be sub-optimal due either to information uncertainty or agent malfunction.

Information uncertainty. Information uncertainty occurs when either one or more of pieces of the 
incoming information for a particular problem are not available or one or more of pieces of incoming information are erroneous.

Agent malfunction. Agent malfunction occurs when either one or more analysts are not available to help the organization solve the problem and so do not report their decisions to their manager, or one or more analysts are unable to report to their superior because the communication channel is unavailable between them, or one or more analysts leave the organization and are replaced by new analysts.

\section{$\underline{\text { Number of Sub-optimalities }}$}

Crises can vary in the extent to which things go wrong. At a simple level, we can think of the organization as being faced by one, two, or three sub-optimalities. That is, there are one, two or three cases where the information is uncertain or the agents malfunction. In this paper, when multiple sub-optimalities occur they are all of the same type.

\section{Organizational Performance}

Our dependent variable is organizational performance. In the organizational literature, many measures of organizational performance have been suggested such as accuracy (Carley 1991 1992; Orasanu and Salas 1992; Pete et al. 1991), effectiveness (Mackenzie 1978; Pfeffer and Salancik 1978), and efficiency (Mackenzie 1978; Scott 1987). In many cases, accuracy, effectiveness, and efficiency are indistinguishable. In crisis response, accuracy can mitigate the impact of the crisis thus producing effective and efficient performance. We measure performance as the percentage of the organizations' choices, during some period, that match the true state of the task environment, i.e., the accuracy of decision choice. Being accurate does not mean that the organization avoids crises. However, it does mean that the organization is correctly classifying outcomes and so is reducing the severity of what actually happens relative to the severity of what potentially could happen. We measure organizational performance both in general and during a crisis. For the in general condition, we measure performance across all 19,683 possible events with nine attributes and three values under all levels of sub-optimalities (none, one, two, or three). For the during crisis condition we measure performance across just those events defined to be hostile and where there are one or more suboptimalities. 


\section{COMPARISON PROCESS FOR MATCHED ANALYSIS}

As noted, we created a set of 69 pairs of organizations - real and artificial organizational performance. Some of the real organizations, however, respond to crisis events by re-structuring, i.e., by changing either the organizational authority structure or the resource access structure or both. Thus, we simulated the real organization using an analog model for both its pre-crisis and its during crisis design and stress portfolio. By using these two sets of data (real and artificial), we can compare organizational performance before and during crisis. Using both the before and the during crisis performance data we can begin to see to what extent the simulation model can predict reality. In addition, this technique, of simulating the artificial organization before and after the restructuring allows us to use static comparisons to do a type of what if analysis. We can ask, using this simulated data, what would have happened if the organization had or had not altered its design. This allows us to use the model both to predict behavior, and to assess whether the actions taken by the organizations (in this case altering their designs) was or was not the most reasonable course of action.

For the most part the way in which the real organizations and their analogs are characterized is identical. The biggest discrepancy between the measures used on the real and artificial data is for performance. Performance is measured differently for the two types of data. In generating the performance of the artificial organizations we took a Monte Carlo approach. The performance of each organization was estimated across a number of independent decisions. This provides a reasonable point estimation of expected performance on specific trial. In the real organizations we only have performance on a single trial. Thus we are using the simulated data to provide an expected behavior of overall performance, not to predict a specific decision.

The second, and more critical difference is that, for CORP, performance is measured as the percentage of correct decisions on a continuous scale from 0 to 100 percent. For the real data, performance is measured on a three-point scale, low moderate, and high. To facilitate comparison we re-categorized the continuous scale used for the artificial organizations into a three-point scale. We located the number of low, moderate, and high performers in the 69 real cases using performance during crisis. There are 28 low, 31 moderate, and 
10 high. Second, we ordered the crisis performance of the matching 69 artificial organizations from low to high. Then we categorized the performance of the lowest 28 artificial organizations as low performers, the next 31 as moderate performers, and the top 10 as high performers. This same strategy was used for both pre-crisis performance and crisis. For pre-crisis performance there are 21 low, 36 moderate, and 11 high performers.

Although the way in which performance is characterized is not identical, they are both reasonable alternatives for estimating general average performance on decision tasks. By using a three-point scale, we are treating both approaches at a sufficiently coarse grain that vagaries due to the specific decision task are made less relevant. We note that the approach we have used is particularly relevant for general performance and crisis performance where the performance of the real organization is an ensemble qualitative estimate of the overall performance that takes in to account a large number (often 100s) of individual decisions. There is reason, based on the case studies, to expect that the better more accurate these individual decisions the higher the overall performance. Similarly, the simulation model gives an indicator of general performance as a function of accuracy. General performance, not specific performance is being predicted.

We find general agreement between model and reality. The Spearman correlation between the artificial and real organizations for general performance is $0.705(\mathrm{p}<0.000)$. This correlation drops to 0.553 $(\mathrm{p}<0.000)$ for performance during crisis. This suggests that the relative impact of different organizational designs and stress is similar in the simulation framework and the corporate world. We now turn to a more detailed analysis.

\section{DESIGNING FOR HIGH PERFORMANCE}

We begin by asking whether the organizational design that exhibits highest performance during a crisis is also optimal under non-crisis conditions. We see (Table 4) that for both the artificial and the real organizations, performance in general and during crisis is to some degree congruent. Notably, for experientially trained organizations, teams with non-segregated resource access structures do tend to be the highest performers under all conditions in both the model and in the real data. For operationally trained organizations, the organization with the highest performance during crisis (team with a segregated structure) 
is not the highest performer in general (although it is one of the higher performers). As compared with the highest performer (team with a non-segregated structure in general situation), a severe degradation of performance is shown. These results suggest that the optimal design for crisis may not be the optimal design in general.

*** Place Table 4 about Here ***

Training, unlike the other elements of design, does have a consistent effect on performance. According to the simulation framework, experientially trained organizations will outperform operationally trained organizations both in general and during a crisis (see Table 5). Experientially trained organizations rely on the experience of their personnel in evaluating current problems. This enables the organization to take advantage of fluidity of individual behavior. Operationally trained organizations rely on the ability of the personnel to follow rigid procedures. On average, experiential organizations will outperform operational organizations as they have more flexibility in attending to any particular problem. Similarly, in the real world, we observe that experientially trained organizations generally perform better than operationally trained organizations both during crisis and on average (Table 5).

*** Place Table 5 about Here $* * *$

Training also affects the relationship between crisis and performance. Common wisdom, as we have noted, is that crises degrade performance and that planning can to an extent mitigate this degradation. However, the prediction derived from CORP is that for experientially trained organizations performance may actually be better during crisis conditions than in general. Whereas, under a crisis situation, performance degrades for operationally trained organizations (see Table 5). In the real world, we observe the predicted pattern (see Table 5). The flexibility of being able to rely on previous experience allows the experiential organization not only to sustain the uncertainty that the crisis engenders but also to adapt to the novel environment. In contrast, organizations of operationally trained personnel have more trouble coping with the uncertainty inherent in a crisis situation. These results suggest that crises, in and of themselves, are not sufficient to degrade performance, rather, organizations can learn to be high performers given a crisis. These results also suggest that the value of planning lies not in the plan (for even operational organizations 
may have plans) but in the added flexibility that going through planning provides if organizational members are allowed from their own experience.

Another prediction derived from CORP is that for experientially trained organizations as more things go wrong (more sub-optimalities) organizational performance degrades (see Table 6). Essentially, within the framework, sub-optimalities can decrease the amount of incoming information and/or increase its ambiguity. Both changes lower the quality of the information available to the individual decision maker. For the experientially trained agent, who has fairly strong latitude in making decisions, the reduction in information quality leads effectively to an increased range of possible outcomes. This in turn reduces the agent's chance of being accurate, which in turn reduces the organization's performance. In the real world we observe that sub-optimalities similarly degrade performance for experientially trained organizations (see Table 6). In both the framework and the real world we see a different pattern for operationally trained organizations. Indeed, having two things go wrong, rather than just one, can actually improve performance. For the operationally trained agent, who has a fairly narrow latitude in making decisions, a moderate reduction in information quality leads effectively to a decreased range of possible outcomes. This in turn can increase the agent's chance of being accurate, which in turn improves the organization's performance. However, in the framework, if there are too many sub-optimalities information quality may be so severely affected that performance will degrade. In our 69 cases we do not observe this "U" shaped relationship between suboptimalities and performance. This result should be viewed with caution as we have only two cases with three or more sub-optimalities. For the real world, how many sub-optimalities are "too many" may be higher than in the framework. However, this speculation should be treated with caution given the paucity of cases with more than two sub-optimalities.

*** Place Table 6 about Here ***

In the artificial organizations we observe that the impact of the sub-optimality on organizational performance depends on what it was that went wrong. Basically, if the error is attributable to agents, organizational performance is lower than if it is attributable to the quality of the incoming information (see Table 7). This is true whether the organizational members are trained to follow experience or standard 
operating procedures. If we think of the organization as a stack — information, agent, managers — then errors at the agent level occur higher than at the information level. The lower down the error in the organizational stack the greater the chances that it can be fixed, overcome, or obliterated by another error. The higher the error occurs in the organizational stack the fewer the opportunities to mitigate its effects. Thus, the higher the error in the organizational stack the lower the organizational performance. We see this same pattern in the real data (see Table 7).

*** Place Table 7 about Here $* * *$

\section{DYNAMIC ADAPTATION}

Finally, let us consider the role of organizational restructuring. As noted in the introduction, it may not be reasonable to use the same organizational design under both crisis and non-crisis conditions. Indeed, the designs that perform best under crisis are not always the designs that perform best in general. Organizations in the corporate world may restructure under certain situations. Staw, Sanderlands, and Dutton (1981) argue that organizations are likely to become rigid when stressed and that such rigidity may help organizational performance if the organization is facing a simple environment. This rigidity can be viewed as a movement to a more complex organization structure (such as a hierarchy) that is centralized though not necessarily redundant. Other researchers advocate increasing structural redundancy to decrease rigidity in access and maintain flexibility (Thompson 1967; Mintzberg 1979; La Porte and Consolini 1991; and Roberts 1990). Still others (Shaw 1981) advocate decentralized organizations as the design that can respond quickly to complex tasks and so should perform better during crisis situations. We examine the value of organizational restructuring using static comparison techniques for both the artificial and the real organizations.

We find, among the 69 real organizations that 38 out of 69 organizations altered either their organizational authority structure or their resource access structures or both when confronted with a crisis. These organizations switched their designs toward more complex designs, not necessarily more rigid designs. The number of restructurings in resource access structure is eight times as large as the number of restructurings in organizational authority structure. This suggests that organizations are more likely to maintain existent lines of communication and authority during crises but are more likely to restructure who 
has access to what and responsibility for what. Of all the 69 organizations, only 31 did not alter either their organizational authority or resource access structures.

This data supports the argument that organizations faced with crises do increase their structural redundancy, they do move to flexibility in accessing information and resources. However, it does not tell us whether this increase in redundancy has value. To answer this question we turn to a form of "what if" analysis. Using the framework we examine the performance of these organizations under the condition that they did, and that they did not alter their design. Thus we can ask the hypothetical question, what if the organizations had not altered their design?

The framework suggests that whether or not the organization should alter its design, given that a crisis has occurred, depends on whether the personnel are trained experientially or operationally (see Table 8). For experiential organizations, performance improves when crises occur whether or not the organization alters its design. For operational organizations performance degrades when crises occur whether or not the design is altered. As predicted by our model we observe performance improvements during crisis for experientially trained organizations and performance degradations for operationally trained organizations whether or not they restructured. Clearly, some organizational restructurings lead to higher performance (or less degradation) than do non-restructurings.

\section{*** Place Table 8 about Here ***}

Using simulation we can move a step beyond this finding. The CORP simulation model predicts that for the experiential organization, the organization will see less of an improvement in performance due to crisis if it alters design. Thus, experiential organizations that actually do restructure their when faced with a crisis may mistakenly attribute the improvement in performance to the restructuring. In this case, experiential organizations that alter designs when faced with crises may mistakenly attribute the improvement in performance to the fact that they altered their design. When in fact, these same organizations might have experienced even greater gains in performance had they not restructured. In contrast, for the operational organization performance degrades when crises occur whether or not the organization alters its design. Further, for the operational organization, the organization will see less 
degradation in performance due to crisis if it does restructure. In this case, operational organizations that alter designs when faced with crisis may mistakenly interpret their degradation in performance as attributable, at least in part, to having altered their design. When in fact, these same organizations might have experienced even more performance degradation had they not restructured. Clearly these "what if" predictions cannot be tested with the particular real data we have used in this paper. However, the general fit between model and data suggests the plausibility of this analysis. Future work, perhaps in an experimental setting, might look at this issue in more detail.

\section{DISCUSSION}

This study has examined the relationship between strategic design and performance for organizations under normal and crisis operating conditions. We took the stand that crises are essentially inevitable and asked how should organizations be designed to mitigate the effect of the crisis. Our study showed that sometimes a crisis could occur even due to some seemingly minor miscues of the organizations and that if organizations were not properly designed to mitigate the impact of the crisis, disasters could occur. Our paper also argues that not all organizational design are best suited for both crisis and non-crisis situations and that adaptation during a crisis situation requires a full understanding of the prior organizational design and the nature of the task environment.

We also examined whether the organization should alter its design when faced with a crisis. Our results indicate that, both in theory and in practice, performance is so conditional that the same design is rarely best for both non-crisis and crisis conditions. Further, organizations, depending on the training and decision-making procedure, can benefit from restructuring when faced with crises. However, organizations may misinterpret the effect of altering their design. This study has strong implications for strategic management as it has demonstrated the impact of organizational design for strategic decision-making but also specified the boundary conditions for critical environmental conditions.

Our analysis, although exploratory, shows a consistent pattern of behavior across both theory and practice: (1) Sub-optimalities generally degrade organizational performance, but the effect of suboptimalities depends on the type of sub-optimalities and the organizational design. (2) There is no 
organizational design that universally performs best. Rather, organizations must adjust their design to their expectations of crisis in order to maintain or achieve good performance. (3) Allowing organizational members to follow their experience in making decisions rather than following standard operating procedures produces better performance in general and during crisis. However, the advantage of experience is higher under crisis conditions. Further, although experiential organizations are better performers, their performance degrades more as stress builds up, whereas operational organizations are more immune to stress. Consequently, the perception of high performance may be higher for operational than experiential organizations. (4) Organizations do alter their designs during crises. Such restructurings are generally toward a more complex organizational form with greater flexibility in access to resources. Whether an organization actually benefits from such a restructuring, or just perceives that it has benefited, depends on how organizational members are trained.

This organizational restructuring phenomenon is very interesting. It shows that during crises, organizations tend to expand their ties to have better control of resources, instead of simply becoming leaner (Hermann 1963; Staw, Sanderlands, and Dutton 1981). The crisis cases we have collected are often major disasters that are somewhat beyond the resource capacity of the organizations involved. Organizations had to increase their resource access to alleviate the crises although this restructuring increased their structural redundancy. We observe more of an increase in resource-to-people links than in people-to-people links; whereas, most researchers have focused on change in people-to-people links (Krackhardt and Stern 1988; La Porte and Consolini 1991). Had we looked at economic crises, or less severe crises, we may have witnessed greater changes in the organizational authority structure.

There are several questions raised by this analysis. For example, why in the corporate data is the performance worse for particular experientially trained organizations than for their operationally trained counterpart under crisis conditions? The reason might be that unlike the computational framework in which experientially trained agents have perfect memory, agents in the corporate world are more limited and less able to apply the lessons of history, particularly under the severe emotional stress that some of these crises can cause. A second reason may have to do with the degree to which the crisis was a truly novel event. The 
crises examined in the computational framework were not completely novel (rare, but not novel). Simulated crisis events were similar in kind to the problems faced by organizations in general, just more extreme. Whereas, in a few of the real events, the crisis may have been a more novel event.

There are limitations to this study in the computational framework, the data on the corporate world, and the overall experimental design. On the one hand, the framework assumes that the organization is faced with a task choice and must choose between three options and that the agents in the organizations receive adequate feedback to learn. In the real world, however, the organization may or may not be facing a choice task, and even if it is facing a choice task there may be more than three choices. Further, many organizational tasks are such that there is not adequate feedback.

On the other hand, the data is drawn from multiple archival sources and there may be potential noise and bias in the coding of the cases due to the intents of the original authors. The real world organizations are often more complex in their design than the idealized structures used in the framework. Thus, the map between artificial organization and real organization is not perfect. For example, in some real organizations there were multiple different errors such as missing information and incorrect information occurring at the same time, while in our computational framework, all errors were of the same type. Further, our analysis for the real organizations crosses multiple industries. Though we have attempted to control for industry features, there may still be problems in equating performance across different industries. Finally, this study is about organizational performance, but the measure of such performance in the real world is in many cases difficult to obtain, due to both the lack of information and the lack of consensus on this measure. We used the outcome of the crisis as the main indicator of organizational performance during crisis.

Further, from an experimental design perspective these data (both framework and real) are limited. The human organization cases only cover a small spectrum of the possible space (many more cases can be examined using the framework). The computational framework we have used can be used to generate a much wider variety of predictions than do those examined herein. We have focused on those predictions for which, in our set of 69 cases, there is sufficient data to admit even a rudimentary test. In a sense, these 69 cases can be viewed as admitting only exploratory studies of the framework as they do not cover the full 
space described by the computational framework. For example, each real organization was faced with a crisis caused by both human error and external threat. This is only one of the operating conditions that can be examined (Lin and Carley 1992). The 69 cases cover only $2 \%$ of the cells that can be studied in the simulation experiments. Clearly an advantage of simulation is that it offers a very powerful method to systematically examine the relative performance of many types of organizations across a wide range of conditions.

In addition, the distribution of real organizational cases is not balanced. For example, the number of experientially trained organizations is far less than that of operationally trained organizations. This limits the analysis. Despite these limitations of the framework, the data, and the experimental design the results are quite striking and provide important insight into organizational performance under crisis conditions.

Despite these limitations, we believe this study has its significant contributions. First of all, this study examines both artificial and real organizations. This combined analytic approach is relatively unique. Frequently, mathematical and computational models are presented sans empirical data and empirical data sans a formal model. It is not our intention to denigrate any of this work. Formal modeling is necessary for theory development. Empirical studies are necessary for testing theory. This paper, however, is relatively unique in that it enables an artificial-real comparison that is valuable, despite all the caveats about the limitations of the data set and the exactness of the fit between the artificial and the real organizations. This is a non-trivial feat, and few studies fall in this intersection. Nevertheless, combined studies such as this are important so that we do not fall prey either to developing theories that build on theory rather than reality or to developing ad hoc explanations of reality that do not consider underlying processes. From a validation standpoint, the approach we used was to do a matched analysis is relatively unique. Most validation studies focus on demonstrating that a set of hypothesis or general trends from the model hold in the empirical data across all of these data. Here we literally matched the simulated and real organizations. This afforded a more detailed level of validation. It also made it possible for us to engage in a "what if" policy exploration using the validated model. As such, this study demonstrates an important use of computational analysis for theory building; to move into the realm of informed alternative state analysis ("what if reasoning"). 
Second, this study has viewed a crisis event as fundamentally an organizational issue and effectively demonstrated the benefit of adopting an organizational design approach to crisis management. In contrast to prior studies of crisis management, this study did not focus on the avoidance of crises but on the mitigation of error. This approach is consistent with the view that crises may be to some extent unavoidable given the increasingly complexity of today's organization and the increasing competitiveness of today's environment. This research demonstrates that a simple neo-information-processing framework for examining organizational performance can provide insight into, and predict the behavior of, human organizations reasonably well during both crisis and non-crisis settings. It provides a demonstration that many claims in the literature about organizational performance emerge from a set of simple processes (in this case the processes embodied within the computational framework) and are true only under special circumstances. This places crisis performance as a special case of general performance.

Third, this study has implications beyond the field of crisis management. Although our research question centers on organizational designs under crisis situations, the findings are relevant to the broad field of strategic management. The study has not only provided useful directions for organizations to understand the environmental niche but also suggested effective strategic designs for organizations to be successful. Our study has also echoed the resource-based view of the firm for developing task-specific knowledge through learning and restructuring, as a means for competitive advantage (Barney 1991). Our study, however, has further pointed out the boundary conditions that arise under different conditions.

Fourth, this study has shown the effectiveness of computational modeling. As an extension of human cognition, computer models can help researchers reason through different perspectives and yield more systematic insight with its ability to "control all the variables under consideration, manipulate them to uncover their effects on dependent variables over time, examine all possible combinations and interactions of variables, and examine the dynamic effects of the variables" (Lant 1994: 196). Computer modeling, therefore, can serve as a special type of virtual laboratory experiment that allows the systematic exploration of complex systems in dynamic settings (Burton and Obel 1984). Scholars such as Axelrod (1997) have also called for a computational modeling approach toward many of the organizational phenomena that are non- 
linear and mathematically inexpressible. With the tool of computational modeling, researchers can now express theories through the programming language, which may also provide a strong alternative for integrating the often segmented and sometimes even contradictory literature in organization science (Harrison 1998; Pfeffer 1993). Computational modeling, with its strong analytical and quantitative capability, enables researchers to move beyond the limits of traditional contingency theory and information processing theory by providing a unified framework in which the disparate findings can emerge from a set of underlying processes operating upon contextualized inputs, and thereby generating concrete and precise insights far beyond those possible by other approaches.

Computational modeling, like any other research method, has its own limitations. First, in order to express complex and mathematically inexpressible relations, a computational model, in particular, one using artificial intelligence techniques as being the case of this study, has to rely on high-level programming languages that are often abstract and distinct from conventional mathematical expressions. Detailed understanding may require examining the computer code, which can easily be over thousands of lines. When compared with mathematical modeling, computational modeling puts a higher demand on the researcher to make code available and provide a clear description for future model replications. Secondly, as a special form of laboratory study, the computer model must walk the line between high generalizability and high veridicality. Highly generalizable models often cannot be validated. CORP is not generalizable to all organizational situations, but only to those with the key characteristics stylized in this paper. This limitation enabled us to engage in the validation study presented. With the further development of the computing technology and real time data capturing techniques future studies should be able to consider more aspects of real world environmental dimensions, organizational features, and individual characteristics (Lin and Carley 1995 1997).

This study has made a serious attempt to extend organizational theory into the complex area of crisis management. Despite the limitations discussed, we believe the approach used in this study and the results from this study provide new directions for future research, both empirically, methodologically and theoretically, which can significantly expand our thinking and advance the field of organization science. We 
have focused on organizational design and restructuring under crisis situations and provided systematic evidence for understanding the nature of organizational restructuring. The study has implications not only to crisis management but also to the broader field of strategic management. In particular, the adaptation analysis where alternative possible states were examined is particularly telling. We find empirical evidence that in response to crises, organizations should move to complex structures with greater resource access. Further, the computational analysis suggests that the lessons organizations learn when they adapt may be the opposite of what they should be learning. If this is the case, then the way in which organizations should design to encourage adaptation, and the very nature of organizational adaptation needs to be reconsidered in terms of the value of alternative paths, not just the value of the path taken. 


\section{REFERENCES}

Aldrich, Howard E. 1979. Organizations and Environment. Prentice Hall, Englewood Cliffs, NJ.

Allison, Graham T. 1971. Essence of Decision: Explaining the Cuban Missile Crisis. Scott, Foreman and Company.

Axelrod, R. 1997. The Complexity of Cooperation: Agent-Based Models of Competition and Collaboration. Princeton University Press, Princeton, NJ.

Baligh, H. H., R. M. Burton, and B. Obel. 1990. Devising Expert Systems in Organization Theory: The Organizational Consultant. In Michael Masuch (Ed.) Organization, Management, and Expert Systems, 35-57. Walter De Gruyter, Berlin.

Barney, J. B. 1991. Firm resources and sustained competitive advantage. Journal of Management, 17, 99120.

Bigley, Gregory A. and Karlene H. Roberts. 2001. The incident command system: High-reliability organization for complex and volatile task environments. Academy of Management Journal, 44, 6, 1281-1300.

Burton, Richard M. and Borge Obel. 1995. The Validity of Computational Models in Organizations Science: From Model Realism to Purpose of the Model. Computational and Mathematical Organization Theory, 1, 1, 57-71.

Carley, Kathleen M. 1992. Organizational Learning and Personnel Turnover. Organization Science, 3, 1, 2 46.

Carley Kathleen M. 1996. A comparison of artificial and human organizations. Journal of Economic Behavior and Organizations, 31, 2, 175-191.

Carley, Kathleen M. 2002a. Inhibiting Adaptation. In Proceedings of the 2002 Command and Control Research and Technology Symposium. Conference held in Naval Postgraduate School, Monterey, CA. Evidence Based Research, Vienna, VA.

Carley, Kathleen M. 2002b. Intra-Organizational Computation and Complexity. In Joel A.C. Baum (Ed.) Companion to Organizations. Blackwell Publishers.

Carley, Kathleen M. and Less Gasser. 1999. Computational organization theory. In Gerhard Weiss (Ed.) Multiagent systems: A modern approach to distributed artificial intelligence: 299-330. Cambridge, MA: MIT Press.

Carley, Kathleen M. and John R. Harrald. 1997. Organizational Learning Under Fire -- Theory and Practice. American Behavioral Scientist, 40, 3, 310-332.

Carley, Kathleen M. and Michael J. Prietula. 1994. ACTS Theory: Extending the Model of Bounded Rationality. In Kathleen Carley and Michael Prietula (Eds.) Computational Organization Theory, 5588. Lawrence Erlbaum Associates, Hillsdale, NJ. 
Carley, Kathleen M. \& Vanessa Hill, 2001. Structural Change and Learning within Organizations. In Alessandro Lomi and Erik R. Larsen (Eds.) Dynamics of Organizations: Computational Modeling and Organizational Theories, Ch. 2. pp 63-92. Live Oak: MIT Press/AAAI Press.

Carley, Kathleen M. and Zhiang Lin. 1995. Organizational Designs Suited to High Performance Under Stress. IEEE Transactions on Systems, Man, and Cybernetics, 25, 2, 221-230.

Carley, Kathleen M. and Zhiang Lin. 1997. A Theoretical Study of Organizational Performance Under Information Distortion. Management Science, 43, 7, 976-997.

Carley, Kathleen M., Michael J. Prietula and Zhiang Lin. 1998. Design Versus Cognition: The Interaction of Agent Cognition and Organizational Design on Organizational Performance. Journal of Artificial Societies and Social Simulation, 1, 3, 1-19.

Cohen, Richard. 1988. Blaming Men, not Machines. Time, August 15, 1988, 19.

Davis, S. M. and P. R. Lawrence. 1977. Matrix. Addison Wesley Publishing Company, Reading, MA.

Drabek, Thomas E. and Gerard J. Hoetmer. (Eds.) 1991. Emergency Management: Principles and Practice for Local Government. International City Management Association, Washington, D.C.

Duffy, Brian, Roberts Kaylor, and Peter Cary. 1988. How Good is this Navy, anyway? U.S. News and World Report, July 18, 1988, 18-19.

Galbraith, Jay R. 1977. Organization Design. Reading, MA: Addison Wesley.

Hall, Richard H. 1991. Organizations: Structures, Processes, and Outcomes. Prentice Hall.

Harrald, J., H. Marcus, and W. Wallace. 1990. The Exxon Valdez: An Assessment of Crisis Prevention and Management Systems. Interfaces, 20, 5, 14-30.

Harrison, J. R. 1998. The Concept of Simulation in Organizational Research. Paper presented at the SCANCOR Conference, Samples of the future, Stanford University, September 1998.

Havron, M. D. and R. L. Blanton. 1977. Simulation for Crisis Management. Human Sciences Research, Inc., McLean, VA.

Hermann, Charles F. 1963. Some Consequences of Crisis Which Limit the Viability of Organizations. Administrative Science Quarterly, 8, 343-358.

Hollenbeck, J. R., Ilgen, D. R., Sego, D. J., Hedlund, J., Major, D. A, and Phillips, J. 1995. The multi-level theory of team decision making: Decision performance in teams incorporating distributed expertise. Journal of Applied Psychology, 80, 292-316.

Hollenbeck, J. R., Ilgen, D. R., Tuttle, D., and Sego, D. J. 1995. Team performance on monitoring tasks: An examination of decision errors in contexts requiring sustained attention. Journal of Applied Psychology, 80, 685-696.

Hutchins 1991, Organizing work by adaptation. Organizational Science, vol. 2, pp. 14-39.

Kim, L. 1998. Crisis Construction and Organizational Learning: Capability Building in Catching-up at Hyundai Motor. Organization Science, 9, 4, 506-521. 
Krackhardt, David and Robert N. Stern. 1988. Informal Networks and Organizational Crises: An Experimental Simulation. Social Psychology Quarterly, 5, 12, 123-140.

La Porte, Todd R. and Paula M. Consolini. 1991. Working in Practice But Not in Theory: Theoretical Challengers of 'High-Reliability Organizations'. Journal of Public Administrative Research and Theory, 1, 1, 19-47.

Lagadec, Patrick. 1981. Major Technological Risk: An Assessment of Industrial Disasters. Pergamon Press, Translated from French by H. Ostwald. 1982, Anchor Press Ltd.

Lant, Theresa. K. 1994. Computer Simulation of Organizations as Experiential Learning Systems: Implications for Organization Theory. In K. M. Carley and M. J. Prietula (Eds.) Computational Organization Theory, 195-216. Lawrence Erlbaum Associates, Hilladale, NJ.

Levinthal, D. A. and Warglien, M. 1999. Landscape Design: Designing for Local Action in Complex Worlds. Organization Science, 10, 3, 342-357.

Lin, Zhiang. 2000. Organizational Restructuring and the Impact of Knowledge Transfer. Journal of Mathematical Sociology, 24, 2, 129-149.

Lin, Zhiang and Chun Hui. 1999. Should Lean Replace Mass Organization Systems: A Theoretical Examination from A Management Coordination Perspective. Journal of International Business Studies, 30, 1, 45-80.

Lin, Zhiang and Kathleen M. Carley. 1992. Maydays and Murphies: A Study of the Effect of Organizational Design, Task, and Stress on Organizational Performance. Paper presented at the 1992 Annual Meeting of the American Sociological Association.

Lin, Zhiang and Kathleen M. Carley. 1995. DYCORP: A Computational Framework for Examining Organizational Performance Under Dynamic Conditions. Journal of Mathematical Sociology, 20, 2-3, 193-217.

Lin, Zhiang and Kathleen M. Carley. 1997. Organizational Response: The Cost Performance Tradeoff. Management Science, 43, 2, 217-234.

Mackenzie, Kenneth D. 1978. Organizational Structures. AHM Publishing Corporation, Arlington Heights, Illinois.

March, James G. \& Herbert Simon. Organizations. New York: John Wiley \& Sons, Inc.,.

March, James G. and John P. Olsen. 1976. Ambiguity and Choice in Organizations. Universitetsforlaget, Bergen.

March, James G., Lee S. Sproull, and Michal Tamuz. 1991. Learning from the samples of one or fewer. Organization Science, 2, 1, 1-13.

Marcus, Alfred A. and Mary L. Nichols. 1999. "On the edge: Heeding the warning of unusual events. Organization Science, 10, 4, 482-499.

McKelvey, B. 1999. Avoiding Complexity Catastrophe in Coevolutionary Pockets: Strategies for Rugged Landscapes. Organization Science, 10, 3, 294-321. 
Mihavics, Ken and Aris Ouksel. 1996. "Learning to Align Organizational Design \& Data." Computational \& Mathematical Organization Theory. 1(2): 143-155.

Newell, A., 1990. Unified Theories of Cognition. Cambridge, MA: Harvard University Press.

Orasanu, Judith and Eduardo Salas. 1992. Team Decision Making in Complex Environments. In G. Klein, J. Orasanu, and R. Calderwood (Eds.) Decision Making in Action: Models and Methods. Ablex Publishing Corp., Norwood, NJ.

Pauchant, Thierry C., Ian I. Mitroff, Douglas N. Weldon, and Gerald F. Ventolo. 1990. The Ever-expanding Scope of Industrial Crises: a Systemic Study of the Hinsdale Telecommunications Outage. Industrial Crisis Quarterly, 4, 243-261.

Perrow, C. 1984. Normal Accidents: Living with High Risk Technologies. Basic Books, Inc.

Pete, Andras, Krishna R. Pattipati, and David L. Kleinman. 1991. Optimal Team and Individual Decision Rules in Uncertain Dichotomous Situations. Working Paper, University of Connecticut.

Pfeffer, Jeffrey and Gerald R. Salancik. 1978. The External Control of Organizations. Harper and Row, New York.

Pfeffer, Jeffrey. 1993. Barriers to the Advance of Organizational Science: Paradigm Development As a Dependent Variable. The Academy of Management Review, 1, 84, 599-620.

Price, James L. 1977. The Study of Turnover. Iowa State University Press, Iowa.

Price, James L. and C. W. Mueller. 1981. Professional Turnover: The Case of Nurses. Jamaica, NY: Spectrum Publications.

Reason, James. 1998. Broadening the cognitive engineering horizons: More engineering, less cognition and no philosophy of science, please. Ergonomics, 41, 2, 150-152.

Roberts, K. 1990. Some Characteristics of One Type of High Reliability Organizations. Organization Science, 1, 2, 160-176.

Roberts, Karlene H. 1997. The Challenger Launch Decision: Risky Technology, Culture, and Deviance at NASA. Administrative Science Quarterly, 42, 2, 405-410.

Rochlin, Gene I. 1991. Iran Air Flight 655 and the USS Vincennes: Complex, Large-scale Military Systems and the Failure of Control. In Todd R. La Porte (Ed.) Social Responses to Large Technical Systems: Control or Anticipation. Kluwer Academic Publishers, Printed in the Netherlands.

Rolfe, J., D. Saunders, and T. Powell, (Eds.) .1998. Simulation and Games for Emergency and Crisis Management. Kogan Page, London.

Rosenthal, U. and B. Pijnenburg. 1991. Crisis Management and Decision Making: Simulation Oriented Scenarios. Kluwer Academic Publishers, Boston, MA.

Sagan, Scott D. 1997. The Challenger Launch Decision: Risky Technology, Culture, and Deviance at NASA. Administrative Science Quarterly, 42, 2, 401-405. 
Schoonhoven, Claudia Bird. 1981. Problems with Contingency Theory: Testing Assumptions Hidden in the Language of Contingency Theory. Administrative Science Quarterly, 26, 349-377.

Scott, W. Richard. 1987. Organizations: Rational, Natural, and Open Systems. Prentice Hall Inc., Englewood Cliffs, New Jersey.

Shaw, M. E. 1981. Group Dynamics: the Psychology of Small Group Behavior. McGraw-Hill.

Shrivastava, Paul. 1987. Bhopal: Anatomy of a Crisis. Ballinger Pub. Co., Cambridge, MA.

Shull, Fremont A., Jr., Sndre L. Delbecq, and L. L. Cummings. 1970. Organizational Decision Making. McGraw-Hill Inc.

Simon, H. A. 1947. Administrative behavior. Free Press, New York.

Staw, Barry M., Lance E. Sanderlands, and Jane E. Dutton. 1981. Threat-Rigidity Effects in Organizational Behavior: A Multilevel Analysis. Administrative Science Quarterly, 26, 501-524.

Sterman, J. D. and Wittenberg, J. 1999. Path Dependence, Competition, and Succession in the Dynamics of Scientific Revolution. Organization Science, 10, 3, 322-341.

Tamminga, Harriet, Thomas S. Kilijanek, Christopher Adams. 1981. Managing Multiorganizational Emergency Responses. University of Colorado Press, Seven Springs, Colorado.

Tang, Zhuang-Bo, Krishna R. Pattipati, and David L. Kleinman. 1991. An Algorithm for Determining the Decision Thresholds in a Distributed Detection Problem. IEEE Transactions on Systems, Man, and Cybernetics, 2, 11, 231-237.

Thompson, James D. 1967. Organizations in Action. McGraw-Hill, New York.

Vaughan, Diane. 1990. Autonomy, Interdependence, and Social Control: NASA and the Space Shuttle Challenger. Administrative Science Quarterly, 35, 2, 225-257.

Walker, W. E. .1995. The Use of Scenarios and Gaming in Crisis Management Planning and Training. RAND, Santa Monica, CA.

Watson, Russel, John Barry and Richard Sandza. 1988. A Case of Human Error. Newsweek, August 15, 1988, 18-21.

Weick, Karl E. 1997. The Challenger Launch Decision: Risky Technology, Culture, and Deviance at NASA. Administrative Science Quarterly, 42, 2, 395-401.

Weick, Karl E. and Karlene H. Roberts. 1993. Collective Minds in Organizations: Heedful Interacting on Flight Decks. Administrative Science Quarterly, 38, 357-381.

\footnotetext{
${ }^{1}$ Code book entries are quite detailed. A copy of the codebook can be obtained from the authors upon request.

${ }^{2}$ CORP is written in $\mathrm{C}$ for the unix environment. It is available upon request from the authors.
} 
Figure 1: A Conceptual Overview of the Theoretical Framework

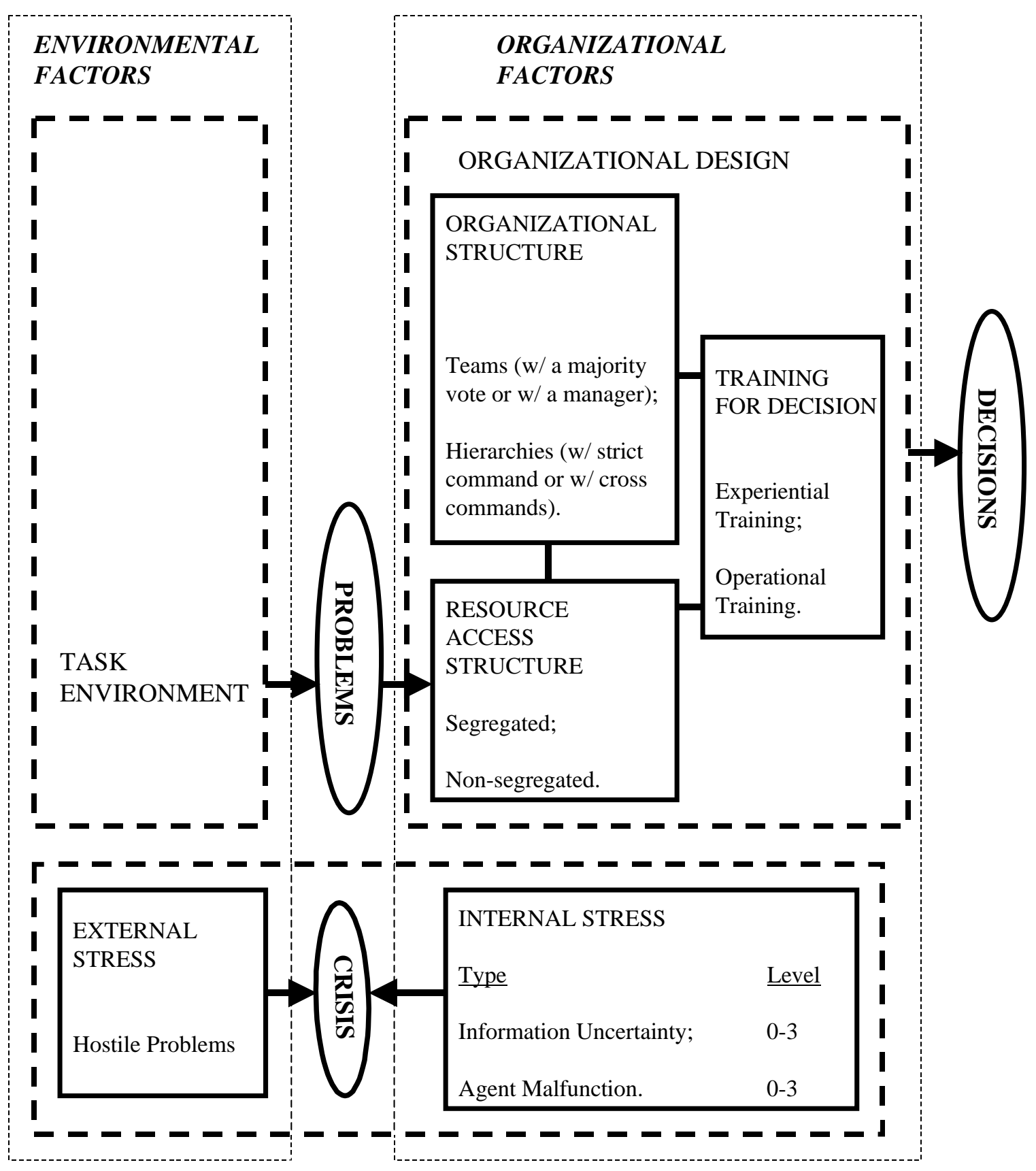


Figure 2: Excerpt from the Code Book

\section{"18 ORGANIZATIONAL STRUCTURE PRIOR TO INCIDENT}

This item refers to how communication flowed in the organization prior to the incident. This is a categorical variable: team (TE), hierarchy (HR), and other (OT).

(1) TE - Team structure. Communication links are predominantly lateral. Final decisions are often collective actions of the group, but there can also be a dominant leader. For example, in the Louisiana mine case (Case No.56), the organizational structure is a team. Workers formed a group. Also in the Three Mile Island incident (Case No.51), the organizational structure of the control room is a team structure. The group of operators worked under a group leader.

(2) HR - Hierarchy structure. Communication is predominantly vertical, flowing between organizational levels. There can sometimes be cross divisional communications. The top-level is the key decision making body and has the most power. For example, in the Vincennes incident (Case No.68), the organizational structure is a hierarchy. There were three predominant levels of management: radar operators, supervisors, and the commanding officer (the captain). Also in the Love Canal incident (Case No.7), the organizational structure is also a hierarchy. Each local unit worked under and reported to several different managers.

(3) OT - Other. Any structure that does not fit into any of the above categories. " 


\begin{tabular}{|c|c|c|c|c|c|}
\hline \# & Case Name and Cause & Industry & Location & Year & Source(s) \\
\hline 1 & Leakage of toxic gas at Bhopal & Chemical & India & 1984 & $5,37,38,39,40$ \\
\hline 2 & Explosion of non-confined vapor at Flixborough & Chemical & Britain & 1974 & 1,2 \\
\hline 3 & Aerosol of solid toxic product at Sevesco & Chemical & Italy & 1976 & 1,2 \\
\hline 4 & $\begin{array}{l}\text { Explosion of gunpowder factory at } \\
\text { Saint Marcel d'Ardeche }\end{array}$ & Chemical & France & 1962 & 1 \\
\hline 5 & Explosion of ammonianitite at the port of Texas & Chemical & U.S. & 1947 & 1,2 \\
\hline 6 & Explosion of non-confined gas cloud at Feyzin & Chemical & France & 1966 & 1 \\
\hline 7 & Pollution of chemical s at Love Canal, Niagara Fall & Chemical & U.S. & 1978 & $1,2,48,49,50,51,52,53,54$ \\
\hline 8 & Explosion of chemicals at Chemstar & Chemical & Britain & 1981 & 14 \\
\hline 9 & Leaks of white sulfuric acid fume at Staveley Chemicals & Chemical & Britain & 1981 & 14 \\
\hline 10 & Explosion of ammonium nitrate at Cory's warehouse & Chemical & Britain & 1982 & 14 \\
\hline 11 & Explosion of chemicals at Dow Chemicals & Chemical & Britain & 1977 & 14 \\
\hline 12 & Explosion of chemicals at Laporte Industries. & Chemical & Britain & 1982 & 14 \\
\hline 13 & Explosion at ManroProducts Itd. & Chemical & Britain & 1975 & 14 \\
\hline 14 & Release of ethyl acrylate by Sybron, at New Jersey & Chemical & U.S. & 1988 & 16 \\
\hline 15 & Pollution of chemical products by Manville Corporation & Chemical & U.S. & 1978 & 18 \\
\hline 16 & Collapse of a chemical storage tank in Pocatello, Idaho & Chemical & U.S. & 1978 & 2 \\
\hline 17 & Fire explosion of a huge heater in Louisiana & Chemical & U.S. & $19 ? ?$ & 2 \\
\hline 18 & $\begin{array}{l}\text { Sinking of the shipLash Atlantico due to collision } \\
\text { with Hellenic Carmer at Kitty Hawk }\end{array}$ & Navigation & U.S. & 1981 & 2 \\
\hline 19 & Sinking of the tankshipS.S. Transhuron & Navigation & Arabian Sea & 1974 & 2 \\
\hline 20 & Sinking of the tankship Tangnari & Navigation & Unuguay & 1978 & 1,2 \\
\hline 21 & Sinking of the Titanic & Navigation & Britain & 1912 & 2 \\
\hline 22 & Collision with a bridge by the ship Summit Venture & Navigation & U.S. & 1980 & 2 \\
\hline 23 & Sinking of the cargo shipU.S. Steel Vendor & Navigation & Pacific Ocean & 1971 & 2 \\
\hline 24 & Explosion of the tankship Cheveron Hawaii & Navigation & U.S. & 1979 & 2 \\
\hline 25 & Collision of another vessel by the ship American Legion & Navigation & U.S & 1981 & 2 \\
\hline 26 & Collision of the vessel Cuyahoga and Santa CruzII & Navigation & ChesapeakeBay & 1978 & 1,2 \\
\hline 27 & Fire of the tanker General Slocumin New York Harbor & Navigation & U.S. & 1904 & 2 \\
\hline 28 & Collision of Keytrader and Baune in Mississippi river & Navigation & U.S. & $19 ? ?$ & 2 \\
\hline 29 & Collision of Trade Master and Pisces in Mississippi river & Navigation & U.S. & 1982 & 2 \\
\hline 30 & Crash of a DC-10inNewZealand & Aviation & NewZealand & 1979 & 1,2 \\
\hline 31 & A Nearcrash of aDC-8 in New York area & Aviation & U.S. & 1982 & 1,2 \\
\hline 32 & Crash of a DC-10inChicago area & Aviation & U.S. & 1979 & 1,2 \\
\hline 33 & Shot down of Kal 007 & Aviation & South Korea. & 1983 & 11 \\
\hline 34 & Crash of aDC-10atErmenonville & Aviation & Turkey & 1974 & 1 \\
\hline 35 & Crash of a United 232at Souix City & Aviation & U.S. & 1989 & $15,56,57,58,59,60$ \\
\hline 36 & Crash of the R-101 & Aviation & France & 1930 & 1 \\
\hline 37 & Collision of airplanes at the Orange Berets, Los Angles & Aviation & U.S. & 1981 & 2 \\
\hline 38 & Disappearance of the Dixumde & Aviation & France & 1923 & 1 \\
\hline 39 & Fire on atrain at Couronnes,Paris & Railroad & France & 1903 & 1 \\
\hline 40 & Crashing of a train at Lagny Pomponne,Paris & Railroad & France & 1933 & 1 \\
\hline 41 & Train accident at Hixon & Railroad & Britain & 1968 & 1,9 \\
\hline 42 & Explosion of a train in Toronto & Railroad & Canada & 1979 & 1,11 \\
\hline 43 & Leak of oil from an oil platformat Ekofisk & Oil & France & 1977 & 1 \\
\hline 44 & Collapse of an off shore oil platformat Bohai & Oil & China & 1980 & 1 \\
\hline 45 & Financial Incident of Pertamina & Oil & Indonesia & 1975 & 10,73 \\
\hline 46 & Leak of oil by Ashland in Pittsburgh & Oil & U.S. & 1988 & $13,70,71$ \\
\hline 47 & Leaking of oil by the Amoco-Cadizat Nordfinistere & Oil & Britain & 1978 & 1,72 \\
\hline 48 & Leaking of oil by the Exxon oil tank at Alaska & Oil & U.S. & 1989 & $6,29,30,31,32,33,34$ \\
\hline 49 & Spill of oil from the Ixtoc oil well in the Gulf of Mexico & Oil & Mexico & 1979 & 1 \\
\hline 50 & Explosion of nuclear plant at Chemobyl & Nuclear & U.S.S.R. & 1986 & $7,42,45$ \\
\hline 51 & Leak of nuclear radiation at Three Mile Island & Nuclear & U.S. & 1977 & $1,2,43,44,45,46,47$ \\
\hline
\end{tabular}


52 Nuclear accidents at San Onofre

53 Explosion of mineatCoumieres

54 Collapse of a mine at Stelerton

55 Sliding of colliery tip from a mountain at Aberfan

56 Mining Accident at Louisiana

57 Explosion of the Space Shuttle Challenger

58 Explosion of the Apollo 13

59 Riots at Haizel Stadium

60 Riots at Belmar, New Jersey

61 Fire at Summerland

62 Collapse of the Grand Teton Dam

63 FireatCinq

64 FireatSaoPaulo

65 Agriculture Incident atEthiopia

66 Religious conflict(Move) at Philadelphia

67 Breakdown of communication at Hinsdale

68 Shooting down of civilian plane by the Vincennes

69 U.S.S. Saritoger firing missiles at a Turkish destroyer

\begin{tabular}{llcc} 
Nuclear & U.S. & 1980 & 1 \\
Mining & Germany & 1906 & 1 \\
Mining & U.S. & 1992 & 6 \\
Mining & Britain & 1966 & 1,9 \\
Mining & U.S. & 1980 & 2 \\
Space & U.S. & 1986 & $3,4,35,36$ \\
Space & U.S. & 1970 & 2,6 \\
Entertainment & Belgium & 1985 & 11 \\
Entertainment & U.S. & 1992 & $12,61,62,63$ \\
Construction & Britain & 1965 & 1,9 \\
Construction & U.S. & 1976 & 2 \\
Construction & Britain & 1973 & 1 \\
Construction & France & 1974 & 1 \\
Agriculture & Ethiopia & 1984 & $11,68,69$ \\
Religion & Philadelphia & 1985 & $11,64,65,66,67$ \\
Communication & U.S. & 1988 & 17,41 \\
Military & PersianGulf & 1988 & $8,19,21,22,23,24,25,26,27$ \\
Military & PersianGulf & 1992 & 20 \\
\hline
\end{tabular}


Main Sources:

[1] Lagadec, Patrick. (1981). Major Technological Risk: An Assessment of Industrial Disasters. Pergamon Press. Translated from French by H. Ostwald. 1982. Anchor Press Ltd.

[2] Perrow, C. (1984). Normal Accidents: Living with High Risk Technologies. Basic Books, Inc.

[3] Rogers, W. P., et al. (1986). Report of the Presidential Commission on the Space Shuttle Challenger Accident. Washington, D.C.: Government Printing Office.

[4] Lewis, Richard S. (1988). Challenger, the Last Voyage. Columbia University Press.

[5] Shrivastava, Paul. (1987). Bhopal: Anatomy of a Crisis. Cambridge, Mass. Ballinger Pub. Co.

[6] Videos, Newspapers, and TV News.

[7] Silver, L. Ray. (1987). Fallout from Chernobyl. Deneau Publishers and Company Ltd.

[8] U.S Congress. (1988). Iran Airflight 655 Compensation Hearings before the Defense Policy Panel of the Committee on Armed Services, House of Representatives, Second Session (Held on August 3, and 4, September 9, and October 6, 1988). U.S Government Printing Office, Washington, D.C., 1989.

[9] Turner, A. Barry. (1976). "The Organizational and Inter-organizational Development of Disasters." Administrative Science Quarterly, Vol.21, Pp:378-397.

[10] Lipsky, Seth (eds.). (1978). The Billion Dollar Bubble...and Other Stories from the Asian Wall Street Journal . Dow Jones Publishing Company (Asia). Inc.

[11] Rosenthal, U., Michael, T. Charles, and Paul 'T Hart (eds.). (1989). Coping with Crises: the Management of Disasters, Riots and Terrorism. Charles C. Thomas, Publisher, Springfield, Illinois, U.S.A.

[12] CNN News Report. (1992). CNN News Report, June 9, 1992.

[13] Comfort, Louise, Joel Abrams, John Camillus, and Edmund Ricci. (1989). "From Crisis to Community: the Pittsburgh Oil Spill." Industrial Crisis Quarterly 3: 17-39.

[14] Tombs, Steve. (1989). "Deviant Workplaces and Dumb Managements? Understanding and Preventing Accidents in the Chemical Industry." Industrial Crisis Quarterly, 3: 191-211.

[15] Charles, T. Michael and Allen K. Settle. (1991). "United Flight 232: Sioux City's Response to an Air Disaster." Industrial Crisis Quarterly, 5: 77-90.

[16] Chess, Caron, Michael Tamuz, Alex Saville and Michael Greenberg. (1992). "Reducing Uncertainty and Increasing Credibility: the Case of Sybron Chemicals Inc.." Industrial Crisis Quarterly, 6: 55-70.

[17] Pauchant, Thierry C., Ian I. Mitroff, Douglas N. Weldon, and Gerald F. Ventolo. (1990). "The Ever-expanding Scope of Industrial Crises: a Systemic Study of the Hinsdale Telecommunications Outage." Industrial Crisis Quarterly, 4: 243-261.

[18] Powell, C. Thomas. (1991). "Shaken, but Alive: Organizational Behavior in the Wake of Catastrophic Events." Industrial Crisis Quarterly, 5: 271-291.

[19] Rochlin, Gene I. (1991). "Iran Air Flight 655 and the USS Vincennes: Complex, Large-scale Military Systems and the Failure of Control." In Todd R. La Porte (Ed.) Social Responses to Large Technical Systems: Control or Anticipation. Kluwer Academic Publishers. Printed in the Netherlands.

[20] CNN News Report. (1992). CNN News Report, December 1, 92.

[21] Yurechko, John. (1992). "Political Science - Storm Center: The USS Vincennes and Iran Air Flight 655 by Sharon Rogers and Will Rogers with Gene Gregston," Library Journal, v117n16, 107.

[22] Carlson, David R. (1989). "Why was Flight 655 Shot Down," Harper's, v279n1674, 26-28.

[23] Time. (1988). "Failure to Communicate," Time, v132n25, 30.

[24] Bower, R. (1988). "'Human Factors' and Militarily Decisions," Science News, v134n16, 245.

[25] Griffiths, Dave. (1988). "When Man Can't Keep Up with the Machines of War," Business Week, n3069, 36.

[26] Aviation Week \& Space Technology. (1988). "Despite Advanced Technologies, Aegis' Identification Ability Limited," Aviation Week \& Space Technology, v129n2, 19-20.

[27] Economist. (1988). "The Flightpath to Disaster," Economist, v308n7558, 43-44.

[28] Cockburn, Alexander. (1988). "The Fog of War," New Statesman and Society, v1n5, 18-19.

[29] National Parks (1992). "Valdez Spill Still Affecting Alaska," National Parks, v66n7-8, 13-14.

[30] Cole, Charles E. and David C. Campbell. (1992). "At Issue: Is \$1 Billion Sufficient Payment for the Exxon Corp.'s Role in the Exxon Valdez Oil Spill?" CQ Researcher, v2n2, 41.

[31] Hodgson, Brian. (1990). "Alaska's Big Spill — Can the Wilderness Heal?" National Geographic, v177n1, 4-43.

[32] Williams, David E. and Glenda Treadaway. (1992). "Exxon and the Valdez Accident: A Failure in Crisis Communication," Communication Studies, v43n1, 56-64.

[33] Benoit, Ellen. (1989). "The Valdez Legacy," Financial World, v158n13, 82-83.

[34] Marshall, Eliot. (1989). "Valdez: the Predicted Oil Spill," Science, v244n4900, 20-21.

[35] Covalut, Craig. (1987). "New Factors Cited in Challenger Accident," Aviation Week and Space Technology, v126n8, 21-22.

[36] Gorton, Slade. (1986). "Pioneering the Space Frontiers: 25 Years Looking Back/Moving Forward," Vital Speeches of the Day, v52n22, 674-678.

[37] Catliff, Nick. (1991). "Bhopal Disaster: Killer in the Night," World Magazine, n47, 76-80.

[38] Bleiberg, Robert M. (1988). "Fresh Disaster at Bhopal: Indian Politics Threaten to Compound the Victims' 

Table 2. Coding of Organizational Performance: A Summary

\begin{tabular}{|c|c|c|c|c|}
\hline \multicolumn{2}{|r|}{$\underline{\text { Potential Severity of Incident }}$} & \multicolumn{3}{|c|}{ Actual Severity of Incident } \\
\hline & & $\begin{array}{l}\quad \text { Low } \\
\text { Incidents of this } \\
\text { scale and impact are } \\
\text { not rare in the } \\
\text { industry. Similar } \\
\text { incidents have } \\
\text { occurred several } \\
\text { times in the history of } \\
\text { the industry. } \\
\text { Example: the } \\
\text { Transhuron incident } \\
\text { (Case No.19). There } \\
\text { were many incidents } \\
\text { of a similar scale and } \\
\text { impact in the } \\
\text { navigation industry. }\end{array}$ & $\begin{array}{l}\quad \text { Medium } \\
\text { Incidents of this scale } \\
\text { and impact are } \\
\text { somewhat rare in the } \\
\text { industry. Similar scale } \\
\text { incidents have occurred } \\
\text { only a few times in the } \\
\text { history of the industry. } \\
\text { Example: the } \\
\text { Ashland Oil Spill } \\
\text { incident (Case No.46). } \\
\text { This spill had less } \\
\text { impact than the Exxon } \\
\text { oil spill, however, spills } \\
\text { of this scale are } \\
\text { infrequently seen in the } \\
\text { oil industry. }\end{array}$ & $\begin{array}{l}\quad \text { High } \\
\text { Incidents of this scale } \\
\text { and impact are very } \\
\text { rare in the industry. } \\
\text { Similar scale incidents } \\
\text { have either never } \\
\text { occurred or are } \\
\text { extremely rare in the } \\
\text { history of the industry. } \\
\text { Example: the } \\
\text { Challenger incident } \\
\text { (Case No.57). The } \\
\text { scale of this incident } \\
\text { was devastating, and } \\
\text { there had never been an } \\
\text { incident of this scale in } \\
\text { the history of space } \\
\text { industry. }\end{array}$ \\
\hline $\begin{array}{l}\underline{\mathrm{L}} \\
\underline{\mathrm{o}} \\
\underline{\mathrm{W}}\end{array}$ & $\begin{array}{l}\text { Incidents have a low potential to be } \\
\text { severe. Given the first sign of the } \\
\text { incident, it is relatively easy to } \\
\text { maintain the scope of the incident and } \\
\text { avoid escalation. } \\
\text { Example: agricultural incidents, } \\
\text { construction incidents, mining } \\
\text { incidents, railroad incidents, religious } \\
\text { incidents, military incidents, and } \\
\text { entertainment incidents. }\end{array}$ & $\begin{array}{l}\text { Medium } \\
\text { Performance. } \\
\text { Example: the } \\
\text { Toronto Rail incident } \\
\text { (Case No.42). }\end{array}$ & $\begin{array}{l}\text { Medium } \\
\text { Performance. } \\
\text { Example: the } \\
\text { Couronnes incident } \\
\text { (Case No.39). }\end{array}$ & $\begin{array}{l}\text { Low Performance. } \\
\text { Example: the } \\
\text { Vincennes incident } \\
\text { (Case No. 68). }\end{array}$ \\
\hline & $\begin{array}{l}\text { Incidents have a moderate potential } \\
\text { to be severe. Given the first sign of the }\end{array}$ & High Performance. & $\begin{array}{l}\text { Medium } \\
\text { Performance. }\end{array}$ & Low Performance. \\
\hline $\begin{array}{l}\frac{\mathrm{M}}{\mathrm{e}} \\
\underline{\mathrm{d}} \\
\underline{\mathrm{i}} \\
\underline{\mathrm{u}}\end{array}$ & $\begin{array}{l}\text { incident, it is moderately possible to } \\
\text { avoid escalation. } \\
\text { Example: chemical incidents, oil } \\
\text { incidents, and navigation incidents. }\end{array}$ & $\begin{array}{l}\text { Example: the } \\
\text { Staveley Chemicals } \\
\text { incident (Case No. } \\
\text { 9). }\end{array}$ & $\begin{array}{l}\text { Example: the Love- } \\
\text { Canal incident (Case } \\
\text { No.7). }\end{array}$ & $\begin{array}{l}\text { Example: the } \\
\text { Pertamina incident (Case } \\
\text { No.45). }\end{array}$ \\
\hline$\underline{\mathrm{H}}$ & $\begin{array}{l}\text { Incidents have a high potential of } \\
\text { catastrophe. Given the first sign of the } \\
\text { incident, escalation cannot be }\end{array}$ & $\begin{array}{l}\text { High Performance. } \\
\text { Example: the }\end{array}$ & $\begin{array}{l}\text { Medium } \\
\text { Performance. }\end{array}$ & $\begin{array}{c}\text { Medium } \\
\text { Performance. }\end{array}$ \\
\hline $\begin{array}{l}\underline{\mathrm{i}} \\
\mathrm{g} \\
\underline{\mathrm{h}}\end{array}$ & $\begin{array}{l}\text { avoided. } \\
\text { Example: nuclear incidents, space } \\
\text { incidents, communication incidents. }\end{array}$ & $\begin{array}{l}\text { Ermenonville } \\
\text { incident (Case } \\
\text { No.34). }\end{array}$ & $\begin{array}{l}\text { Example: the Orange } \\
\text { Berets incident (Case } \\
\text { No.37). }\end{array}$ & $\begin{array}{l}\text { Example: the Space } \\
\text { Shuttle Challenger } \\
\text { incident (Case No.57). }\end{array}$ \\
\hline
\end{tabular}


Table 3. Modeling Task Environments

\begin{tabular}{|c|c|}
\hline Environment Characteristics & Manipulations and Outcomes in the Model \\
\hline \multicolumn{2}{|l|}{ Concentrated Decomposable } \\
\hline Formula & $\Sigma=\mathrm{T} 1+\mathrm{T} 2+\mathrm{T} 3+\mathrm{T} 4+\mathrm{T} 5+\mathrm{T} 6+\mathrm{T} 7+\mathrm{T} 8+\mathrm{T} 9$ \\
\hline Possible Outcomes & 1(Friendly), 2(Neutral), 3(Hostile) \\
\hline Cut-Off Values & 1 if $\Sigma<=13 ; 2$ if $13<\Sigma<=17 ; 3$ if $\Sigma>17$ \\
\hline Distribution of Problems & Friendly: 625; Neutral: 7647; Hostile: 11411 \\
\hline \multicolumn{2}{|l|}{ Dispersed Decomposable } \\
\hline Formula & $\Sigma=\mathrm{T} 1+\mathrm{T} 2+\mathrm{T} 3+\mathrm{T} 4+\mathrm{T} 5+\mathrm{T} 6+\mathrm{T} 7+\mathrm{T} 8+\mathrm{T} 9$ \\
\hline Possible Outcomes & 1(Friendly), 2(Neutral), 3(Hostile) \\
\hline Cut-Off Values & 1 if $\Sigma<=16 . ; 2$ if $16 .<\Sigma<=19 . ; 3$ if $\Sigma>19$. \\
\hline Distribution of Problems & Friendly: 6751; Neutral: 6181; Hostile: 6751 \\
\hline \multicolumn{2}{|c|}{ Concentrated Non-decomposable } \\
\hline Formula & $\Sigma=\mathrm{T} 1 * \mathrm{~T} 2 * \mathrm{~T} 3 * 2+\mathrm{T} 4 * \mathrm{~T} 5 * 2+\mathrm{T} 6 * \mathrm{~T} 7 * \mathrm{~T} 9 * 2+\mathrm{T} 8+\mathrm{T} 9$ \\
\hline Possible Outcomes & 1(Friendly), 2(Neutral), 3(Hostile) \\
\hline Cut-Off Values & 1 if $\Sigma<=20 ; 2$ if $20<\Sigma<=23 ; 3$ if $\Sigma>23$ \\
\hline Distribution of Problems & Friendly: 1131; Neutral: 3321; Hostile: 14631 \\
\hline \multicolumn{2}{|l|}{ Dispersed Non-decomposable } \\
\hline Formula & $\Sigma=\mathrm{T} 1 * \mathrm{~T} 2 * \mathrm{~T} 3 * 2+\mathrm{T} 4 * \mathrm{~T} 5 * 2+\mathrm{T} 6 * \mathrm{~T} 7 * \mathrm{~T} 9 * 2+\mathrm{T} 8+\mathrm{T} 9$ \\
\hline Possible Outcomes & 1(Friendly), 2(Neutral), 3(Hostile) \\
\hline Cut-Off Values & 1 if $\Sigma<=33 ; 2$ if $33<\Sigma<=49 ; 3$ if $\Sigma>49$ \\
\hline Distribution of Problems & Friendly: 6488; Neutral: 6648; Hostile: 6547 \\
\hline
\end{tabular}


Table 4. Organizational Performance by Organizational Form

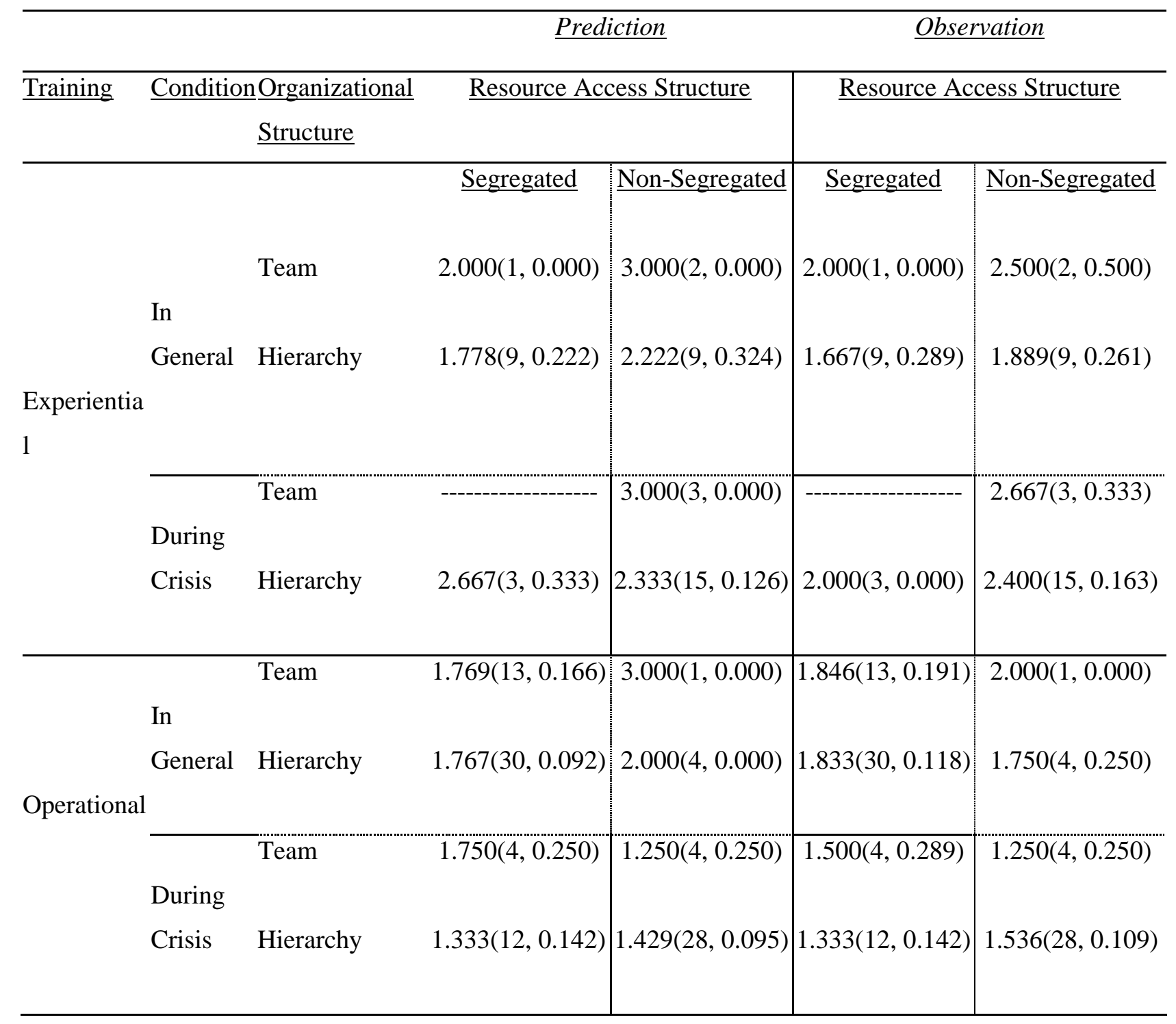

Note: Number of cases and standard errors are in parentheses. A "" refers to insufficient organizational data. 
Table 5. Organizational Performance — An Overall Picture

\section{Prediction}

\begin{tabular}{|c|c|c|}
\hline Training & Performance in General & Performance During Crisis \\
\hline Experiential & $2.10(21,0.18)$ & $2.38(21,0.11)$ \\
\hline Operational & $1.83(48,0.10)$ & $1.42(48,0.07)$ \\
\hline
\end{tabular}

\section{Observation}

\begin{tabular}{lcc}
\hline Training & Performance in General & Performance During Crisis \\
& & \\
Experiential & $1.86(21,0.17)$ & $2.38(21,0.13)$ \\
Operational & $1.83(48,0.09)$ & $1.46(48,0.08)$ \\
\hline
\end{tabular}

Note: Number of cases and standard errors are in parentheses. 
Table 6. Organizational Performance During Crisis by Number of Sub-optimalities

\section{Prediction}

\begin{tabular}{lrrr}
\hline Training & $\underline{1 \text { Sub-optimality }}$ & $\underline{\text { 2 Sub-optimalities }}$ & \\
& & & \\
Experiential & $2.67(9,0.17)$ & $2.18(11,0.12)$ & $2.00(1,0.00)$ \\
Operational & $1.21(24,0.15)$ & $1.68(22,0.10)$ & $1.00(2,0.50)$ \\
\hline
\end{tabular}

Observation

\begin{tabular}{lrrr}
\hline Training & 1 Sub-optimality & $\underline{\text { 2 Sub-optimalities }}$ & $\underline{\text { 3 Sub-optimalities }}$ \\
& & & \\
Experiential & $2.56(9,0.18)$ & $2.27(11,0.20)$ & $2.00(1,0.00)$ \\
Operational & $1.42(24,0.15)$ & $1.50(22,0.11)$ & $1.50(2,0.50)$ \\
\hline
\end{tabular}

Note: Number of cases, and standard errors are in parentheses. 
Table 7. Organizational Performance During Crisis by Type of Sub-optimality

\section{$\underline{\text { Prediction }}$}

\begin{tabular}{lcc}
\hline Training & \multicolumn{2}{c}{ Type of Sub-optimality } \\
& \multicolumn{1}{c}{ Information Uncertainty } & Agent Malfunction \\
\cline { 2 - 3 } Experiential & $2.71(7,0.18)$ & $2.50(2,0.50)$ \\
Operational & $1.24(17,0.11)$ & $1.14(7,0.14)$ \\
\hline
\end{tabular}

\section{$\underline{\text { Observation }}$}

Training Type of Sub-optimality

Information Uncertainty

$\underline{\text { Agent Malfunction }}$

Experiential

$2.57(7,0.20)$

$2.50(2,0.50)$

Operational

$1.53(17,0.16)$

$1.14(7,0.20)$

Note: Number of cases and standard errors are in parentheses. In all cases the number of sub-optimalities is one. 
Table 8. Organizational Performance by Organizational Restructuring

\begin{tabular}{|c|c|c|c|c|}
\hline \multicolumn{5}{|c|}{ Prediction } \\
\hline \multirow[t]{2}{*}{ Training } & \multirow[t]{2}{*}{ Type of Shift } & $\frac{\text { Performance }}{\text { in General }}$ & \multicolumn{2}{|c|}{$\underline{\text { Performance During Crisis }}$} \\
\hline & & Old Form & $\begin{array}{l}\text { Restructured to } \\
\text { New Form }\end{array}$ & $\underline{\text { Retained Old Form }}$ \\
\hline \multirow{5}{*}{ Experiential } & No Shift & $2.286(14,0.244)$ & ---------------- & $2.643(14,0.133)$ \\
\hline & Structure Shift Only & ---------------- & ---------------- & ---------------- \\
\hline & Access Shift Only & $1.714(7,0.184)$ & $2.286(7,0.184)$ & $2.714(7,0.184)$ \\
\hline & Both Shift & --------------- & ---------------- & ---------------- \\
\hline & Either Shift & $1.714(7,0.184)$ & $2.286(7,0.184)$ & $2.714(7,0.184)$ \\
\hline \multirow{5}{*}{ Operational } & No Shift & $2.118(17,0.118)$ & ---------------- & $1.588(17,0.123)$ \\
\hline & Structure Shift Only & $1.250(4,0.250)$ & $1.000(4,0.000)$ & $1.250(4,0.250)$ \\
\hline & Access Shift Only & $1.680(25,0.095)$ & $1.320(25,0.095)$ & $1.200(25,0.082)$ \\
\hline & Both Shift & $2.000(2,0.000)$ & $2.000(2,0.000)$ & $1.500(2,0.500)$ \\
\hline & Either Shift & $1.645(31,0.087)$ & $1.323(31,0.085)$ & $1.226(31,0.076)$ \\
\hline \multicolumn{5}{|c|}{$\underline{\text { Observation }}$} \\
\hline \multirow[t]{2}{*}{ Training } & Type of Shift & $\begin{array}{l}\text { Performance } \\
\text { in General }\end{array}$ & \multicolumn{2}{|c|}{$\begin{array}{l}\text { Performance } \\
\underline{\text { During Crisis }}\end{array}$} \\
\hline & & $\underline{\text { Old Form }}$ & $\begin{array}{l}\text { Restructured to } \\
\text { New Form }\end{array}$ & $\underline{\text { Retained Old Form }}$ \\
\hline \multirow{5}{*}{ Experiential } & No Shift & $2.071(14,0.221)$ & ---------------- & $2.500(14,0.139)$ \\
\hline & Structure Shift Only & ----------------- & ---------------- & ----------------- \\
\hline & Access Shift Only & $1.429(7,0.202)$ & $2.143(7,0.261)$ & ----- \\
\hline & Both Shift & -------------- & -------------- & -------------- \\
\hline & Either Shift & $1.429(7,0.202)$ & $2.143(7,0.261)$ & ---------------- \\
\hline \multirow{5}{*}{ Operational } & No Shift & $2.000(17,0.149)$ & ---------------- & $1.588(17,0.123)$ \\
\hline & Structure Shift Only & $1.500(4,0.500)$ & $1.000(4,0.000)$ & ---------------- \\
\hline & Access Shift Only & $1.760(25,0.119)$ & $1.440(25,0.117)$ & ---------- \\
\hline & Both Shift & $2.000(2,0.000)$ & $1.500(2,0.500)$ & ---------------- \\
\hline & Either Shift & $1.742(31,0.113)$ & $1.387(31,0.100)$ & ----------------' \\
\hline
\end{tabular}

Note: Number of cases and standard errors are in parentheses. A "" indicates that there is no data available for that cell. 
